\title{
Prática alimentar de lactentes atendidos pela Estratégia Saúde da Família no Maranhão
}

\author{
Fabiana Corrêa Fernandes
}

Dissertação apresentada ao Programa de Pós-Graduação em Nutrição em Saúde Pública para a obtenção do título de Mestre em Ciências.

Área de Concentração: Nutrição em Saúde Pública

Orientadora: Prof ${ }^{a}$ Dr $^{a}$ Sophia Cornbluth Szarfarc

São Paulo

2015 
Para minha mãe Miraci, meu exemplo de fortaleza, persistência, dedicação e amor aos estudos.

Para minha filha Carolina, para quem Deus permita que eu seja exemplo. 


\section{AGRADECIMENTOS}

Muito obrigada Santíssima Trindade e Nossa Senhora Mãe de Deus e nossa, não foram poucos os momentos dessa jornada que Vós fostes meu único socorro.

Meu profundo obrigada aos meus pais, Miraci e Vinhote, aos quais serei sempre grata pelas inúmeras oportunidades que me proporcionaram. Amo-vos!

Minha linda filha Carolina, teu jeito de ajudar e compreender foram fundamentais. Amo-te incondicionalmente!

Meu amor Arthur, muito obrigada por tanto amor. Tu foste o idealizador desta caminhada, por isto te agradecerei sempre. Foste o que mais sentiu a aspereza desta caminhada, mas tua preocupação, respeito e paciência foram dignos da parceria esperada quando escolhemos uma pessoa para caminhar conosco. Amo-te para sempre!

Meus irmãos Charles, Luciana e Geane, mais uma etapa concluída do que almejamos um dia. Estamos distantes, mas estamos juntos. Muito obrigada pelo apoio!

Professora Dra Sophia, quando a conheci e soube que teria a honra da vossa orientação, só conseguia agradecer, pois desde o começo sabia das dificuldades que enfrentaria nesta jornada e que havia recebido uma graça, ter a orientação de um anjo. Agradeço por compartilhar tanta sabedoria, agradeço por todas as dúvidas esclarecidas, agradeço por todas as sugestões que enriqueceram o trabalho e principalmente agradeço pelas oportunidades nesta jornada. Minha admiração pela mulher e pesquisadora será eterna. Foi uma honra!

Professora Dr $^{\mathrm{a}}$ Tereza Frota, muito obrigada por concordar em disponibilizar os dados do projeto "Prevalência e Determinantes da Anemia em Mulheres e Crianças no Estado do Maranhão”, o que tornou viável esta dissertação e permitiu que uma nutricionista apaixonada por Saúde Pública pudesse contribuir nas discussões acerca de segurança alimentar e inclusão social de famílias brasileiras. 
Muito obrigada professora $\mathrm{Dr}^{\mathrm{a}}$ Regina Fisberg pelas pertinentes sugestões no Exame de Qualificação.

Dr ${ }^{\mathrm{a}}$ Olga Amâncio e $\mathrm{Dr}^{\mathrm{a}}$ Rita Aquino, muito obrigada pela presteza na leitura da dissertação e pelos comentários e reflexões que enriqueceram este trabalho.

Sempre disponíveis, Alessandra e Diego, minhas referência no PPG, muito obrigada pelas orientações e respostas com a rapidez necessária à ansiedade de um estudante de pós-graduação.

Minha querida amiga Adriana, senti muito tua falta neste período, muito obrigada pela torcida e compreensão.

Meus queridos Dr. Ricardo e Antônio, da época que trabalhamos juntos, o maior legado foi o carinho verdadeiro. Muito obrigada pela torcida nesta caminhada.

Minhas queridas amigas Ana Kimie e Gislaine, mais do que parceiras de trabalho, grandes amigas e grandes incentivadoras desta caminhada. Muito obrigada!

Minhas chefes no Hospital Municipal Dr. Cármino Caricchio, Ana Lúcia e Regina, agradeço imensamente todas as formas de apoio manifestadas, seja pelas palavras de carinho nos momentos mais difíceis ou pela compreensão devido as inúmeras trocas de plantão, necessárias à conclusão das atividades do mestrado. Muito obrigada!

Minhas colegas de trabalho, Clau, Juliana, Andreia e Patrícia, obrigada por tornarem nosso ambiente de trabalho emocionante e acolhedor. Nossas conversas, risadas, discussões foram fundamentais quando o cansaço predominava. Um agradecimento especial para Andreia, que num momento decisivo dispôs de material indispensável à conclusão deste trabalho. Obrigada de coração!

Meus filhotes caninos, Tony e Darth Vader, exemplos de doação e amor incondicional. Obrigada por tanta ternura e companhia nas noites de estudo.

Que Deus nos abençoe! 


\section{RESUMO}

Corrêa F. Prática alimentar de lactentes atendidos pela Estratégia Saúde da Família no Maranhão [dissertação de mestrado]. São Paulo: Faculdade de Saúde Pública da USP; 2015.

Introdução - $\mathrm{O}$ intenso crescimento e desenvolvimento da criança nos dois primeiros anos de vida inserem este grupo populacional em situação de alto risco à desnutrição e deficiências nutricionais específicas, especialmente em situações socioeconômicas desfavoráveis. Objetivo - Identificar a prática da alimentação de crianças de 06 a 23 meses de idade atendidas pela Estratégia Saúde da Família no Maranhão. Métodos - Dados secundários do projeto Prevalência e Determinantes da Anemia em Mulheres e Crianças no Estado do Maranhão. Estudo transversal de base populacional e abordagem quantitativa. O consumo foi avaliado através do inquérito Recordatório de 24 horas. A avaliação da adequação de consumo foi realizada através do Guia Alimentar para Crianças Menores de 2 anos, do Guia Alimentar para a População Brasileira e pelo proposto pela Pesquisa Nacional de Saúde. A prática alimentar foi caracterizada pela frequência de refeições, participação dos grupos de alimentos e quantificação de energia, ferro e vitamina A, distribuídos por faixa etária. Resultados - Das 401 crianças com idade entre 06 e 23 meses, 52\% ainda eram amamentadas, sendo para $17 \%$ a única fonte láctea. O grupo dos leites e derivados foi o mais frequente em todas as crianças com $65 \%$ entre 6 a 8 meses, $53 \%$ de 9 a 11 meses, $41 \%$ de 12 a 17 meses e $29 \%$ de 18 a 23 meses, declinando expressivamente com o aumento da idade. O grupo de cereais, tubérculos e derivados, o segundo mais expressivo, aumenta com a idade, com frequência de $11 \%, 16 \%$, 24\% e $28 \%$, respectivamente em cada faixa etária. Os alimentos mais consumidos em cada grupo foram leite materno associado ao leite de vaca, arroz, banana, legumes como ingrediente principal da papa salgada, feijão, carne bovina, açúcar, margarina e refresco. Frutas, legumes e verduras, considerados marcadores de padrão alimentar saudável, tiveram um consumo de 13,3\%,14,0\%, 14,8\% e 16,1\%, por faixa etária. O consumo de alimentos marcadores de padrão alimentar não saudável variou de $6 \%$ entre 6 e 8 meses a 16\% entre 18 a 23 meses. A quantidade média de energia, ferro e vitamina A foram de $880 \mathrm{Kcal}, 5,2 \mathrm{mg}$ e $395 \mu \mathrm{gRE}$ e inadequação em relação às recomendações de $41 \%, 75 \%$ e $57 \%$, respectivamente, para crianças de todas as faixas etárias. Valores de inadequação de ferro foram elevados principalmente na faixa etária entre 9 e 11 meses de idade com 97\% de inadequação. Em relação à vitamina A, verificamos 76,3\% de inadequação entre 18 e 23 meses de idade. A adequação de energia foi de 95,4\%. Conclusão - Constatou-se que a alimentação de grande parte da população não atende às recomendações nutricionais de ferro e vitamina A. Igualmente, por ser constituído basicamente por uma dieta láctea, consumo elevado de alimentos energéticos e reduzido consumo de frutas, legumes e verduras, não atende à segurança alimentar. Os resultados obtidos mostram o risco de anemia e hipovitaminose A. Igualmente, a prática alimentar aponta para o risco do desenvolvimento de doenças crônicas, evidenciando a necessidade de aprimoramento das ações de orientação de hábitos alimentares saudáveis na Atenção Básica. 
Descritores: consumo de alimentos, desmame, deficiências nutricionais, estratégia saúde da família. 


\section{ABSTRACT}

Corrêa F. Eating habits of children attending the Family Health Strategy in Maranhão [dissertation]. São Paulo: School of Public Health at USP; 2015.

Introduction - The intense growth and development of children in the first two years of life insert this population group at high risk for malnutrition and specific nutritional deficiencies, especially in unfavorable socioeconomic situations. Objective - To identify the practice of feeding children 06-23 months old served by the Family Health Strategy in Maranhão. Methods - Secondary data from Prevalence and Determinants Projects of anemia in women and children in the state of Maranhão projects. Transversal population-based study and a quantitative approach. Consumption was assessed by dietary recall survey of 24 hours. The assessment of consumption was performed using the Food Guide for Children under two years, the Food Guide for the Brazilian Population and proposed by the National Health Survey. A diet was characterized by frequency of meals, participation in food groups and quantification of energy, iron and vitamin A, divided by age group. Results - From 401 children within 06 to 23 months, 52\% were still being breastfed and for $17 \%$ from this group it was the only milk source. The group of milk and dairy products was the most common in all children with $65 \%$ between 6-8 months 53\% 9-11 months 41\% 12-17 months and 29\% 18-23 months falling significantly as their age increase. The group derived from cereals and tubers, the second most significant, increases with age, often $11 \%, 16 \%, 24 \%$ and $28 \%$ respectively in each age group. The most consumed foods in each group were breast milk associated to cow's milk, rice, banana, soups rich with vegetables, beans, beef, sugar, margarine and artificial fruit refreshment. Fruits and vegetables, that are considered healthy eating pattern markers, had a consumption average of $13,3 \%, 14,0 \%, 14,8 \%$ and $16,1 \%$, by age group. The consumption of unhealthy foods in pattern markers ranged from 6\% between 6 and 8 months to 16\% between 18-23 months. The average amount of energy, iron and vitamin A were $880 \mathrm{kcal}, 5.2 \mathrm{mg}$ and 395 $\mu \mathrm{gRE}$ and inadequacy in relation to the recommendations of $41 \%, 75 \%$ and $57 \%$, respectively, for children of all ages. Inadequacy of iron values were high especially in 9 and 11 months age with $97 \%$ of inadequacy. With regard to vitamin A, we found $76.3 \%$ inadequacy between 18 and 23 months old. The adequacy of energy was 95.4\%. Conclusion - It was noticed that a big part of the population doesn't have access to the nutritional recommendation of iron and vitamin A. Also, since it is basically constituted by a milk diet, high consumption of energy foods and low consumption of fruits and vegetables, does not attend the food safety. The results show the risk of anemia and hypovitaminosis A. Likewise, the feeding practice points to the risk of developing chronic diseases, highlighting the need to improve the orientation of shares of healthy eating habits in primary care.

Keywords: food consumption, weaning, deficiency diseases, family health strategy. 


\section{ÍNDICE}

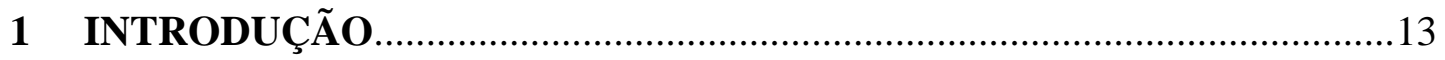

2 OBJETIVOS

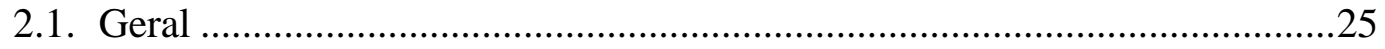

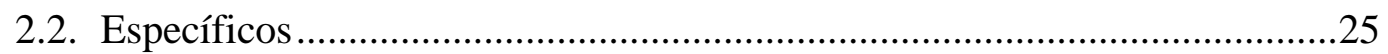

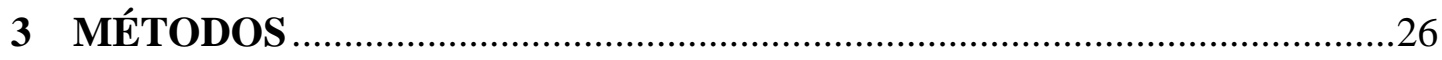

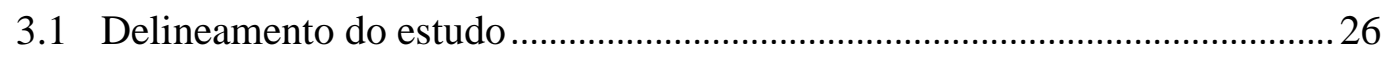

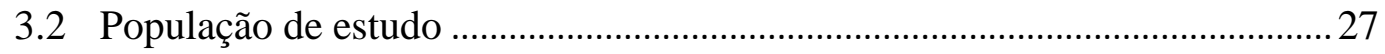

3.3 Processamento e análise de dados .................................................................... 30

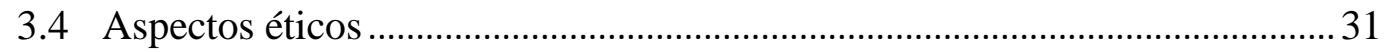

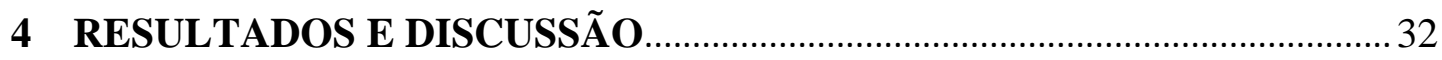

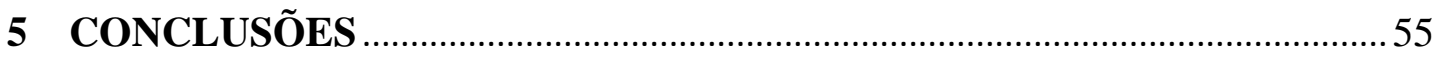

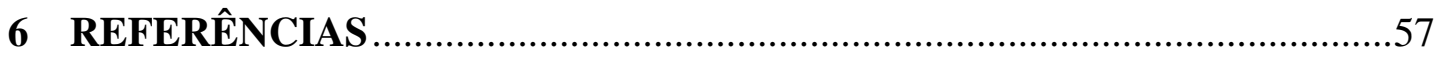

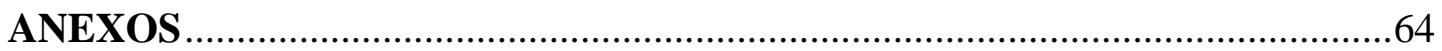

ANEXO I - Parecer consubstanciado do Comitê de Ética em Pesquisa do Hospital Universitário da Universidade Federal do Maranhão ......................................................... 64

ANEXO II - Ofício do Comitê de Ética em Pesquisa da Faculdade de Saúde Pública

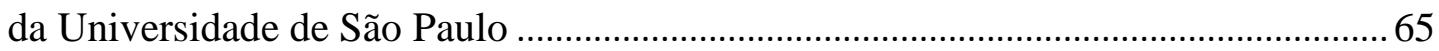

ANEXO III - Termo de Consentimento Livre e Esclarecido .......................................6 66 
ANEXO IV - Questionário da Pesquisa 68 CURRICULUM LATTES 


\section{LISTA DE QUADROS, FIGURAS E TABELAS}

\section{QUADROS}

Quadro 1 - Esquema alimentar para crianças menores de dois anos amamentadas. 15

Quadro 2 - Grupo de alimentos e frequência de consumo, por faixa etária. 28

\section{FIGURAS}

Figura 1 - Percentual de adequação de vitamina A nas crianças, segundo faixa etária. Maranhão, 2010.

\section{TABELAS}

Tabela 1 - Distribuição percentual (\%) dos alimentos consumidos pelas crianças, faixa de idade. Maranhão, 2010.

Tabela 2 - Número de porções per capita por grupos de alimentos, segundo proporção de consumidores e faixa etária. Maranhão, 2010.

Tabela 3 - Distribuição de frequência (\%) dos alimentos segundo marcadores da alimentação, por faixa etária. Maranhão, 2010.

Tabela 4 - Participação relativa (\%) dos alimentos segundo categoria de processamento empregado na produção, por faixa etária. Maranhão, 2010. 
Tabela 5 - Participação relativa (\%) dos grupos de alimentos na disponibilidade total de energia, segundo faixa etária. Maranhão, 2010.

Tabela 6 - Participação relativa (\%) dos principais alimentos fonte de ferro no fornecimento do nutriente, segundo faixa etária. Maranhão, 2010.

Tabela 7 - Participação relativa (\%) dos principais alimentos fonte de vitamina A no fornecimento do nutriente, segundo faixa etária. Maranhão, 2010. 
SIGLAS UTILIZADAS

\begin{tabular}{ll} 
ANVISA & Agência Nacional de Vigilância Sanitária \\
EBIA & Escala Brasileira de Insegurança Alimentar \\
ESF & Estratégia Saúde da Família \\
IDHM & Instituto Brasileiro de Geografia e Estatística \\
LOSAN & Índice de Desenvolvimento Humano Municipal \\
MS & Ministério da Saúde \\
OMS & Organização Mundial de Saúde \\
PNAD & Pesquisa Nacional de Amostra Domiciliar \\
PNAN & Política Nacional de Alimentação e Nutrição \\
PNDS & Pesquisa Nacional de Demografia e Saúde da Criança e da Mulher \\
PNS & Pesquisa Nacional de Saúde \\
PNSP & Programa Nacional de Suplementação de Ferro \\
POF & Pesquisa de Orçamentos Familiares \\
PSF & Programa de Saúde da Família \\
SAN & Segurança Alimentar e Nutricional \\
\hline The & Termo de Consentimento Livre e Esclarecido Health Organization \\
\hline
\end{tabular}




\section{INTRODUÇÃO}

O intenso crescimento e desenvolvimento da criança nos dois primeiros anos de vida inserem este grupo populacional em situação de alto risco à desnutrição e deficiências nutricionais, acentuado a partir dos seis meses de idade, quando o leite materno já não é suficiente para atender todas as demandas nutricionais inerentes a essa fase da vida (BRASIL/OPAS, 2005; WHO, 1998).

O aleitamento materno exclusivo até o sexto mês de vida supre as necessidades nutricionais da criança. Após esse período é necessária a introdução de alimentação complementar adequada para atender às necessidades de energia e micronutrientes, imprescindível ao crescimento e desenvolvimento saudáveis, resguardando a amamentação até dois anos de idade (BRASIL, 2009b; WHO, 2002b; WHO, 1998).

A alimentação complementar deve ser oportuna, adequada, segura em qualidade e quantidade, o que significa que os alimentos devem ser introduzidos quando a necessidade de energia e nutrientes demandadas pelo crescimento excede o que pode ser fornecida através do aleitamento materno exclusivo, que os alimentos forneçam energia, proteínas e micronutrientes suficientes para atender esta demanda, que os alimentos sejam armazenados, preparados e ofertados respeitando práticas adequadas de higiene e que respeitem os sinais de apetite e saciedade da criança (WHO, 2002a).

Alimentação complementar pode ser definida como a oferta de qualquer outro alimento diferente do leite materno a ser oferecido à criança amamentada, especialmente preparados e com alimentos apropriados para esta, até que passem a receber a alimentação da família (BRASIL/OPAS, 2005). 
Em relação às estimativas de energia advindas da alimentação complementar em países em desenvolvimento, assumindo um consumo médio de leite materno, adições através da alimentação complementar de $200 \mathrm{kcal} / \mathrm{dia}$ para crianças com idade entre 6-8 meses, $300 \mathrm{kcal} /$ dia para crianças com idade entre 9-11 meses, e $550 \mathrm{kcal} /$ dia para crianças com idade entre 12-23 meses são adequados para evitar o déficit energético. Os alimentos devem ser oferecidos após os seis meses sob a forma de purês ou amassados, aumentando a consistência conforme o crescimento e adequando-se paulatinamente aos alimentos consumidos pela família. Alimentos com baixa densidade energética são desaconselhados, podendo influenciar no número de refeições. Devem ser oferecidos alimentos variados e que garantam as necessidades nutricionais. Peixes, carnes, ovos, frutas e legumes devem ser consumidos diariamente desde os seis meses de idade. Devem ser evitadas bebidas de baixo valor nutricional como chás, cafés e refrigerantes (WHO, 2002a).

O Ministério da Saúde (MS) endossa esse padrão alimentar como recomendação de saúde pública. Para fortalecer a promoção de práticas alimentares saudáveis nos dois primeiros anos de vida, as ações prioritárias de promoção, proteção, recuperação da saúde e do estado de nutrição dessas crianças estão pautadas em modelos de orientação da alimentação e nutrição como eixo estratégico para promover segurança alimentar, reduzir a morbi-mortalidade na infância, o retardo de crescimento, atraso escolar e prevenir a ocorrência das doenças crônicas na maturidade. Para tanto, orienta práticas alimentares saudáveis para introdução da alimentação complementar de acordo com as recomendações do Guia Alimentar para Crianças Menores de 2 anos, voltado aos profissionais de saúde, onde é proposto um esquema alimentar para época de início da alimentação e frequências oportunas (Quadro 1), bem como que o planejamento da alimentação respeite a identidade cultural e alimentar das populações das diversas regiões, valorizando a produção local de alimentos (BRASIL, 2013). 
Quadro 1 - Esquema alimentar para crianças menores de dois anos amamentadas

\begin{tabular}{|lll|}
\hline Ao completar $\mathbf{6}$ meses & Ao completar 7 meses & \multicolumn{1}{c|}{ Ao completar 12 meses } \\
\hline $\begin{array}{l}\text { Leite materno sob livre } \\
\text { demanda }\end{array}$ & $\begin{array}{l}\text { Leite materno sob livre } \\
\text { demanda }\end{array}$ & $\begin{array}{l}\text { Leite materno e fruta ou cereal } \\
\text { ou tubérculo }\end{array}$ \\
\hline Papa de fruta & Papa de fruta & Fruta \\
\hline Papa salgada & Papa salgada & Refeição básica da família \\
\hline Papa de fruta & Papa de fruta & $\begin{array}{l}\text { Fruta ou pão simples ou } \\
\text { tubérculo ou cereal }\end{array}$ \\
\hline Leite materno & Papa salgada & Refeição básica da família \\
\hline
\end{tabular}

Fonte: BRASIL, 2013.

Não obstante aos esforços nesta área, a II Pesquisa de Prevalência de Aleitamento Materno nas Capitais Brasileiras e Distrito Federal mostrou que somente 73,2\% das crianças entre 6 e 9 meses, período de introdução da alimentação complementar, haviam recebido comida salgada, 69,8\% dessas crianças haviam consumido frutas e 70,9\% verduras/legumes e com relação aos marcadores de práticas não saudáveis da alimentação, mostrou o consumo elevado de café (8,7\%), de refrigerantes (11,6\%) e especialmente de bolachas e/ou salgadinhos $(71,7 \%)$. Com relação ao aleitamento materno exclusivo até o sexto mês de vida e manutenção da amamentação até o segundo ano de vida ou mais, o quadro encontrado ainda apresentou-se distante das recomendações (BRASIL, 2009c). Bem como, a Pesquisa Nacional de Demografia e Saúde da Criança e da Mulher - PNDS 2006 mostrou que a incidência da introdução tardia da refeição de sal, foi de 62,6\% entre as crianças de 6 e 7 meses em aleitamento materno (BRASIL, 2009a).

FARIAS JÚNIOR et al. (2005), analisaram o padrão alimentar de crianças no Estado de Pernambuco e demonstraram uma alimentação monótona, com reduzido consumo de frutas e verduras em crianças menores de 5 anos e que conforme o aumento da idade, alimentos como leite de vaca, amido, alimentos à base 
de cereal e leite materno decrescem de forma progressiva, porém o inverso ocorre com o consumo de gordura, arroz, feijão, carne, biscoito, pão, milho e batata.

OLIVEIRA et al. (2005a) analisaram a alimentação complementar de crianças residentes em Salvador (BA) e observaram o acentuado declínio do leite materno em crianças de 6 a 24 meses, com o aumento no consumo de leite de vaca, cereais e derivados e reduzido consumo médio de verduras, frutas e leguminosas.

CAETANO et al.( 2012) e BERNADI et al. (2009) observaram o consumo precoce e elevado de alimentos industrializados, refrigerantes e guloseimas em crianças de 06 meses a 24 meses.

O desmame precoce, a oferta precoce de alimentos com alta densidade energética, a baixa concentração de micronutrientes, associados a condições socioeconômicas desfavoráveis contribuem para alimentação inadequada, expondo os lactentes ao risco de desnutrições (BERNARDI et al., 2009; CORRÊA et al., 2009; OLIVEIRA et al., 2005a; SOUZA et al., 1999).

Os estudos têm evidenciado que a alimentação das crianças não ocorre como preconizada pelo MS e OMS, mas indicam que as crianças estão expostas a um padrão alimentar que seguramente não fornece os nutrientes necessários ao crescimento e desenvolvimento adequados e a proteção contra doenças.

Alimentação adequada é um direito fundamental do ser humano e no Brasil é um direito Constitucional, inserido na Carta Magna por meio da Emenda Constitucional $n^{\circ} 64$ de 2010, tendo as políticas sociais orientadas fundamentalmente pela Lei Orgânica de Segurança Alimentar e Nutricional - LOSAN (Lei $n^{\circ}$ 11.346/06), que dispõe acerca de Segurança Alimentar e Nutricional (SAN) como a realização do direito de todos ao acesso regular e permanente a alimentos de qualidade, em quantidade suficiente, sem comprometer o acesso a outras necessidades essenciais, tendo como base práticas alimentares promotoras de saúde que respeitem a diversidade cultural e que sejam ambiental, cultural, econômica e socialmente sustentáveis. 
Situações de insegurança alimentar e nutricional podem ser detectadas pela fome, na sua essência, como avaliado pela Escala Brasileira de Insegurança Alimentar (EBIA) (SEGALL-CORRÊA al., 2010), porém outras condições são determinantes da insegurança alimentar como obesidade, doenças associadas à má alimentação, o consumo de alimentos de qualidade duvidosa ou prejudicial à saúde, formas de produção de alimentos prejudiciais ao meio ambiente ou às relações econômicas e sociais, entre outras formas que desrespeitem o direito à soberania alimentar (CONSEA, 2004).

Antunes et al., 2010, observaram em crianças menores de três anos de idade no Distrito de Campos Elíseos, Município de Duque de Caxias, Rio de Janeiro (RJ), em situação de insegurança alimentar avaliado pela EBIA, o consumo de proteínas e ferro significativamente menor que as crianças em segurança alimentar. Quando observaram o consumo por grupos de alimentos, as crianças com insegurança alimentar leve apresentaram maior consumo dos grupos das hortaliças, doces, açúcares e café e menor consumo de cereais. As crianças na forma grave de insegurança alimentar apresentaram consumo reduzido de cereais, hortaliças, frutas, carnes, ovos e gordura, em relação às crianças em segurança alimentar.

Em âmbito mundial, cerca de 30\% das crianças menores de cinco anos apresentam baixo peso por consequência de alimentação inadequada e infecções de repetição (WHO, 2003). Os dados provenientes da PNDS (2006) mostraram que a prevalência de baixo peso para estatura em crianças menores de cinco anos no Brasil é de 1,4\%, baixa estatura para a idade é de 7\% e excesso de peso é de 7,3\% e para crianças menores de dois anos é de 2,7\%, 8,5\% e 6,5\% respectivamente (BRASIL, 2009a). O indicador antropométrico altura/idade, o qual reflete desnutrição passada ou pregressa é o mais comprometido nas crianças e está diretamente relacionado com condições de saúde/doença e alimentação inadequada. Notadamente os valores de déficit de altura para a idade têm valores muito semelhantes aos de excesso de peso.

Carências nutricionais de grande impacto à saúde pública, como anemia ferropriva e a hipovitaminose A também são apresentadas na PNDS (2006). Na pesquisa, a prevalência de anemia, hemoglobina $(\mathrm{Hb})<11,0 \mathrm{~g} / \mathrm{dL}$, em menores de 
cinco anos foi de 20,9\% e naquelas com 6 a 23 meses, 24,1\%. Em relação à vitamina A, valores abaixo de $<0,7 \mu \mathrm{mol} / \mathrm{L}$ foram encontrados em $17,4 \%$ em menores de cinco anos e 16,3\% nas de 6 a 23 meses. Na região Nordeste a prevalência de anemia e hipovitaminose A nas crianças menores de cinco anos foram de 25,5\% e 19,0\%, respectivamente. No Maranhão, FROTA encontrou 65 \% de lactentes com $\mathrm{Hb}<11,0$ g/dL e esta classificação, que indica risco grave para a deficiência de ferro (OMS), também foi encontrada em 36\% nas mulheres em idade fértil. Sendo a alimentação deficiente e/ou inadequada o principal determinante dessas desnutrições são amplamente justificadas as intervenções implantadas com vistas a seu controle: a fortificação de farinhas de trigo e de milho, o Programa Nacional de Suplementação de Ferro (PNSF) e o Programa Nacional de Suplementação de Vitamina A, este restrito as Regiões Norte e Nordeste, e os municípios das Regiões Centro-Oeste, Sul e Sudeste contemplados no Programa Brasil sem Miséria, que objetiva superar a a extrema pobreza no Brasil.

Contrapondo o quadro das doenças carenciais nas crianças, BATISTA FILHO et al., (2008) em avaliação do processo de transição nutricional, concluiram que as prevalências de sobrepeso/obesidade em adultos apresentam-se semelhantes na evolução temporal às doenças carenciais. O aumento das doenças crônicas não transmissíveis, que atingem principalmente adultos e idosos nos países em desenvolvimento caracteriza um processo de transição nutricional, que estaria associado entre outros, às inadequações no consumo alimentar como substrato deste.

Considerando a perspectiva do microambiente familiar como um dos fatores determinantes das deficiências nutricionais, estudos com este enfoque têm mostrado associações entre o estado nutricional de mães e filhos.

MIGLIOLI (2014) encontrou associação em relação à anemia, deficiência de vitamina A e marcadores antropométricos no binômio mãe/filho. O aumento de peso nas crianças estava associado com o aumento de peso de suas mães; mulheres de baixo peso tendiam a ter filhos com deficiência de vitamina A e concentração de hemoglobina da mãe tinha relação direta com níveis de hemoglobina e retinol dos filhos. FROTA (2013), MIGLIOLI (2010) e SILVA et al., (2008) 
verificaram que a presença de anemia materna é fator de risco para anemia em crianças.

De acordo com a Pesquisa Nacional de Saúde (PNS) (IBGE, 2013), onde foram considerados como marcadores de padrão saudável de alimentação o consumo recomendado de frutas, verduras e legumes e o consumo regular de feijão, o percentual de pessoas adultas com 18 anos ou mais que consumiam o recomendado foi de 37,3\% e 71,9\%, respectivamente. Considerados marcadores de padrão alimentação não saudável, o consumo regular de refrigerantes, leite integral, carnes com excesso de gordura e consumo de sal foi de 23,4\%, 60,6\% e 37,2\% e 14,2\%, respectivamente. O consumo regular de alimentos doces, como bolos, tortas, chocolates, balas, biscoitos ou bolachas doces, também considerado marcador de alimentação não saudável foi de 21,7\% (BRASIL, 2013b).

Análises da Pesquisa de Orçamentos Familiares 2008/2009 (POF 2008/2009) (IBGE, 2010), utilizada como base para a elaboração do Guia Alimentar para População Brasileira (BRASIL, 2014), mostrou que alimentos in natura e minimamente processados (arroz, feijão, carnes, frutas, verduras, etc.) e preparações culinárias feitas com esses alimentos correspondem em calorias a dois terços da alimentação dos brasileiros. Sendo assim, um terço da alimentação dos brasileiros já é constituído por alimentos processados ou ultraprocessados (bolos, biscoitos, refrigerantes, salgadinhos, etc.), nutricionalmente desbalanceados, que pela natureza da sua produção favorecem a ingestão excessiva de calorias (BRASIL, 2014).

ROTENBERG et al., (2004), em análise das práticas alimentares de crianças, identificaram que estas práticas tem características sociais, temporais, de saúde e doença, cuidado, afetiva e econômica, devendo ser compreendidas além dos alimentos consumidos, mas também das condições que favorecem este consumo, como a disponibilidade de alimentos, modo de vida, mídia, influências familiares e culturais.

Ao lado das doenças crônicas e obesidade que constituem atualmente a grande preocupação dos profissionais de saúde, deficiências específicas de ferro e 
vitamina A mantêm-se elevadas não obstante as intervenções implantadas para seu controle, como visto na PNDS (2006).

Neste sentido os guias alimentares são instrumentos importantes na orientação de hábitos alimentares saudáveis e as equipes da Estratégia Saúde da Família (ESF) tem um papel relevante na transmissão desses conhecimentos.

Nos dois primeiros anos de vida em que a criança é introduzida na alimentação familiar há a oportunidade ímpar de conscientizar a mãe/família da importância de uma alimentação equilibrada para a criança e sua manutenção para toda a família.

Portanto, conhecer como é realizada a introdução dos alimentos na dieta das crianças e a prática alimentar desta população é conhecer a alimentação da família, as influências sociais e culturais, bem como, os estados carenciais intrafamiliar decorrente de práticas alimentares inadequadas. Assim, esse conhecimento permite prevenir riscos para as crianças e desfecho negativo na sua vida.

A compreensão de que a alimentação adequada é inerente à prevenção das doenças crônicas, bem como a compreensão da nutrição adequada das crianças como estratégia de intervenção nutricional, pode ter efeitos importantes sobre as condições de saúde na fase adulta (BATISTA FILHO et al., 2008; BARRETO et al., 2005).

A educação nutricional deve ser direcionada à família, pois as crianças acolhem hábitos conhecidos. Mudanças para melhor nos hábitos alimentares dos pais podem estimular práticas alimentares saudáveis nos seus filhos (ROSSI et al., 2008). As famílias devem ser orientadas a identificar hábitos alimentares adequados, que lhes proporcionem melhores condições de saúde e bem-estar.

Considerando-se o processo gradativo e sequencial de introdução da alimentação complementar, cujo final é a dieta familiar habitual, e a importância do caráter preventivo de estratégias e ações visando mudanças de hábitos alimentares 
inadequados, salienta-se o mérito em conhecer os alimentos ou grupos de alimentos usados nesse processo introdutório e a frequência com que aparecem em cada idade. Ressalta-se a importância para a situação de segurança alimentar e nutricional, no intuito de compreender uma das causas de afecção à saúde na infância e comportamentos de riscos para doenças crônicas não transmissíveis.

Com esse enfoque, os estudos de padrões de consumo de alimentos de uma população configuram-se como estratégia para o direcionamento de políticas públicas de intervenção, pois como monitoramento populacional os dados de consumo são o primeiro indicador de risco às deficiências nutricionais (TABACCHI et al., 2009; MONTEIRO et al.,2000; GALEAZZI et al., 1997). A identificação do padrão alimentar de crianças é um instrumento importante para o direcionamento de políticas públicas de intervenção, com vistas a promoção, proteção e recuperação de condições adequadas de saúde (BRASIL/OPAS, 2005).

As ações de vigilância alimentar e nutricional no Brasil destinam-se à identificação da situação alimentar e nutricional da população, com vistas a ações de prevenção e controle das carências nutricionais e da promoção de práticas alimentares saudáveis, pautando-se as ações nos principais agravos nutricionais e seus fatores de riscos, como o déficit estatural em crianças; sobrepeso e obesidade e as morbidades associadas em todas as fases da vida; carências nutricionais como anemia ferropriva e a hipovitaminose A.

A Política Nacional de Alimentação e Nutrição (PNAN), aprovada no ano de 1999 e atualizada pela Portaria $n^{0}$ 2.715, de novembro de 2011, ratifica o compromisso do Ministério da Saúde em erradicar os distúrbios nutricionais e as doenças a eles relacionadas. Tem como propósito melhorar as condições de alimentação, nutrição e saúde da população brasileira, através da promoção de práticas alimentares saudáveis, vigilância alimentar e nutricional, prevenção e cuidados integrais aos agravos relacionados à alimentação e nutrição. É diretriz da PNAN a organização da atenção nutricional como parte integral da Rede de Atenção à Saúde, tendo a Atenção Básica como coordenadora e ordenadora da rede (BRASIL, 2012). 
A Estratégia Saúde da Família, criado em 1994, inicialmente como Programa de Saúde da Família (PSF), visa à reorganização da Atenção Básica no País, reorientando o modelo assistencial do SUS centrado na doença. É tida como estratégia de expansão, qualificação e consolidação da atenção básica orientada pelos princípios doutrinários do SUS, a universalidade, a equidade e a integralidade da assistência (BRASIL, 2012b). Esse modelo de atenção, mais próximo da vida das pessoas, auxilia no manejo das necessidades de saúde relevantes a cada território, como a diminuição da mortalidade, aumento das coberturas vacinais e controle das doenças.

No que concerne à promoção de práticas alimentares saudáveis, compete à ESF atuar no incremento das ações de prevenção e controle de carências nutricionais em todo o ciclo da vida, com incentivo ao aleitamento materno, alimentação complementar adequada e oportuna e suplementação de micronutrientes como o ferro e vitamina A (BRASIL, 2012a).

COUTINHO et al. (2011) analisaram o enfrentamento dos problemas nutricionais através das políticas públicas no Brasil e constataram a atuação da ESF como positiva no combate às desnutrições, embora tenha havido o incremento da obesidade e das doenças crônicas não transmissíveis no mesmo período.

Neste sentido a ESF poderá atuar com um enfoque único no combate a este processo de transição nutricional instalado, mantendo o caráter orientativo, multiplicando conhecimentos e informações que auxiliem na resolução deste dilema.

Assim, considerando que as famílias devem ser orientadas a identificar hábitos alimentares adequados que lhes proporcionem condições de escolha e autonomia para perpetuação de hábitos saudáveis, ratifica-se a importância de conhecer a evolução da alimentação, bem como os agravos praticados na alimentação das crianças, de modo a reorientar a forma de atuação da ESF com o propósito de interromper este ciclo prejudicial no qual a população está inserida. 
A cobertura da ESF apresenta ritmo diferenciado segundo o porte populacional dos municípios. Verifica-se que quanto menor o município e mais vulnerável, maior é a cobertura da ESF. Os municípios das regiões Norte e Nordeste, com as menores médias para indicadores socioeconômicos, mais vulneráveis e dependentes de transferências de renda federais são os que mais tiveram aumentada essa cobertura (PORTELA et al., 2011).

Não pode deixar de ser citada a restrição quantitativa de alimentos presentes nas populações carentes. Na região Nordeste 55\% das famílias refere insegurança alimentar (EBIA), dos quais 7\% insegurança alimentar grave, enquanto na região Sul esse valor é de $25 \%$. Acerca das condições socioeconômicas, as diferenças regionais persistem, com cerca de 82,9\% das famílias classificadas como classe média na região Sul, em relação aos somente 35,5\% (sendo 63,1\% nas classes D e E) no Nordeste (PNDS 2006), caracterizando essa região como a mais dependente de programas de políticas sociais. A Pesquisa Nacional de Amostra Domiciliar de 2004 (PNAD) (IBGE, 2004) mostra que nas regiões Norte e Nordeste, cerca de $17 \%$ das crianças menores de cinco anos de idade, viviam em condições de insegurança alimentar em relação à 5,3\% nas regiões Sul e Sudeste.

Situado no Nordeste do Brasil, o Maranhão tem o Índice de Desenvolvimento Humano Municipal (IDHM) de 0,639, ocupando o penúltimo lugar entre os Estados brasileiros. O Estado ocupa os últimos lugares nas listas de renda per capita com R\$ 360,34 e de Expectativa de Vida com 70,4 anos (IBGE, 2010). O Estado do Maranhão apresenta uma cobertura de 100\% dos municípios com equipes credenciadas da ESF, com proporção de cobertura populacional estimada em 81,18\% em julho de 2010, beneficio que se mantém cobrindo 82,53\% dessa população em abril de 2015 (BRASIL/MS/SAS/DAB), sendo que a capital São Luiz é a menos beneficiada pelo programa. Os valores do EBIA (IBGE, 2010) destacam a vulnerabilidade da população atendida pela ESF.

Considerando o panorama social em que o Estado do Maranhão está inserido, bem como a estreita relação entre as deficiências nutricionais e o quadro de pobreza, a identificação da situação alimentar dos lactentes dessa população pode 
subsidiar a implementação de políticas de alimentação e nutrição no Estado, visando prevenir distúrbios nutricionais com a melhoraria das práticas alimentares da população do Estado do Maranhão. 


\section{OBJETIVOS}

\subsection{Geral}

Identificar a prática da alimentação de crianças de 6 a 23 meses de idade atendidas pela Estratégia Saúde da Família no Maranhão.

\subsection{Específicos}

- Estimar a adequação da prática alimentar segundo guias alimentares nacionais;

- Verificar a adequação do consumo energético e de nutrientes selecionados: ferro e vitamina A. 


\section{MÉTODOS}

\subsection{Delineamento do estudo}

Este estudo foi elaborado a partir de dados secundários do projeto "Prevalência e Determinantes da Anemia em Mulheres e Crianças no Estado do Maranhão", coordenado por $\quad$ FROTA, MTB (http://www.teses.usp.br/teses/disponiveis/6/6138/tde-08042013-101924/). É um estudo de corte transversal de base populacional, desenvolvido com o objetivo de avaliar as condições de saúde e nutrição das crianças menores de cinco anos e mulheres em idade reprodutiva no Maranhão e que, além da prevalência de anemia, avaliou aspectos socioeconômicos e demográficos das famílias, estado nutricional, aleitamento materno e consumo alimentar das mulheres e crianças.

A população do estudo foi de famílias com crianças de 6 a 59 meses de idade e de mulheres com 15 a 49 anos de idade, constituída de pares de crianças e mães. A amostra, do tipo probabilística estratificada, foi dimensionada de modo a garantir representatividade para o Estado, para cada macrorregião e para a capital. O cálculo do número de crianças foi baseado na prevalência de anemia na região Nordeste, de 25,5\%, dado relatado na PNDS (2006). O número de mulheres foi estabelecido pela associação simples ao número de crianças. Detalhes da amostragem podem ser vistos em http://www.teses.usp.br/teses/disponiveis/6/6138/tde-08042013101924/.

A pesquisa foi realizada no Estado do Maranhão, entre a população atendida pela ESF, nas suas quatro macrorregiões geográficas (Santa Inês, Caxias, Imperatriz e Pinheiro) e a capital São Luís. 


\subsection{População de estudo}

A amostra constitui-se das 401 crianças, de 6 a 23 meses, identificadas na amostra total de 978 crianças elegíveis para a pesquisa "Prevalência e Determinantes da Anemia em Mulheres e Crianças no Estado do Maranhão”.

As informações referentes ao consumo alimentar foram coletadas por meio do inquérito Recordatório de 24 horas, sendo expressa em medida caseira a quantidade de alimentos referida. Elas foram obtidas diretamente nos domicílios sorteados, com a mãe da criança, biológica ou não.

Para a identificação da composição nutricional dos alimentos foram adotados os dados da Tabela de Composição Nutricional dos Alimentos Consumidos no Brasil (IBGE, 2011). A ela foi acrescentado um campo quantificando a presença do aleitamento materno e outro campo foi incluído para adicionar o ferro suplementar presente nos alimentos derivados das farinhas de trigo e milho fortificado com o nutriente desde junho de 2004 (BRASIL, 2002).

O consumo alimentar foi analisado a partir da frequência dos alimentos e grupos de alimentos e da frequência que os mesmos estão presentes nas refeições das crianças, por faixa etária.

Os grupos de alimentos foram definidos conforme as recomendações do Guia Alimentar para Crianças Menores de 2 anos, de acordo com os grupos propostos pela Pirâmide Alimentar Infantil, representação gráfica do Guia. A entrada dos alimentos e preparações em cada grupo é definida em função dos nutrientes básicos dos alimentos (BRASIL, 2005). 
A participação do alimento no grupo de forma isolada, caracterizando os principais alimentos consumidos pelas crianças, foi determinada mediante $\mathbf{0}$ percentual mínimo de consumo de 5\% deste.

O número de porções de alimentos foi definido em função dos equivalentes de energia (Kcal), conforme demonstrado no Quadro 2.

A análise da frequência de alimentos nos grupos, bem como a frequência das porções na alimentação das crianças consideraram as recomendações do Guia, conforme disposto a seguir:

Quadro 2 - Grupo de alimentos e frequência de consumo, por faixa etária

\begin{tabular}{|c|c|c|c|}
\hline Grupo & $\begin{array}{l}\text { Calorias em } \\
1 \text { porção }\end{array}$ & $\begin{array}{c}\text { Recomendação } \\
\text { diária } 6 \text { a } 12 \\
\text { meses }\end{array}$ & $\begin{array}{c}\text { Recomendação } \\
\text { diária } 12 \text { a } 24 \\
\text { meses }\end{array}$ \\
\hline $\begin{array}{l}\text { Cereais, pães e } \\
\text { tubérculos }\end{array}$ & $75 \mathrm{Kcal}$ & Três porções & Cinco porções \\
\hline $\begin{array}{l}\text { Verduras e } \\
\text { Legumes }\end{array}$ & $8 \mathrm{Kcal}$ & Três porções & Três porções \\
\hline Frutas & $35 \mathrm{Kcal}$ & Três porções & Quatro porções \\
\hline $\begin{array}{l}\text { Leite e produtos } \\
\text { lácteos }\end{array}$ & $120 \mathrm{Kcal}$ & Três porções & Três porções \\
\hline $\begin{array}{l}\text { Carnes, miúdos e } \\
\text { ovos }\end{array}$ & $65 \mathrm{Kcal}$ & Duas porções & Duas porções \\
\hline Leguminosas & 20 Kcal & Duas porções & Duas porções \\
\hline Óleos e gorduras & $37 \mathrm{Kcal}$ & Duas porções & Duas porções \\
\hline $\begin{array}{l}\text { Açúcares, doces e } \\
\text { bebidas }\end{array}$ & $55 \mathrm{Kcal}$ & Nenhuma & Nenhuma \\
\hline
\end{tabular}

Fonte: BRASIL, 2013; BRASIL, 2005. 
As condições de segurança alimentar foram investigadas em relação à presença de alimentos e grupos alimentares segundo propostas do Guia Alimentar para Crianças Menores de 02 anos (BRASIL, 2013), Pesquisa Nacional de Saúde (BRASIL, 2013) e Guia Alimentar para a População Brasileira (BRASIL, 2014).

Para a classificação da condição de segurança alimentar foram considerados os critérios consonantes às recomendações dos guias alimentares que vem sendo utilizados no Brasil:

- O Guia Alimentar para Crianças Menores de 2 anos, considera como condição de segurança alimentar os conceitos de variedade, moderação e proporcionalidade propostos na Pirâmide Alimentar Infantil que dispõem sobre o consumo de alimentos variados e nas porções recomendadas, de acordo com o nível que o grupo alimentar se encontra na Pirâmide;

- A Pesquisa Nacional de Saúde considera como marcadores de padrão saudável de alimentação o consumo recomendado de frutas, verduras e legumes, equivalente ao consumo de $85 \%$ das porções diárias recomendadas para esses alimentos e o consumo regular de feijão e marcadores de padrão alimentar não saudável o consumo de refrigerantes, carnes com excesso de gordura, consumo de sal e de alimentos doces, como bolos, tortas, chocolates, balas, biscoitos ou bolachas doces;

- O Guia Alimentar para a População Brasileira considera como marcador de hábitos saudáveis de alimentação o consumo de alimentos in natura ou minimamente processados, obtidos diretamente de plantas ou animais, como frutas, verduras e legumes, ovos, leite, sem que tenham sofrido quaisquer alterações ou sofreram alterações mínimas, como legumes e verduras congelados e leite pasteurizado e o consumo de produtos beneficiados a partir de alimentos in natura utilizados com moderação em preparações culinárias, como óleos, açúcar e sal. O guia recomenda a utilização de alimentados processados como queijos, pães, frutas em calda, limitados ao uso como parte de refeições a base de alimentos in natura ou minimamente processado e que 
alimentos ultraprocessados como refrigerantes, biscoitos, salgadinhos, macarrão instantâneo, devam ser evitados.

Para a estimativa de consumo do leite materno, considerou-se o volume médio diário consumido de acordo com a idade da criança, estimado a partir de recomendações da WHO (1998) para países em desenvolvimento.

A prática alimentar foi caracterizada através da participação relativa dos alimentos na disponibilidade total de energia. A prevalência de inadequação foi avaliada conforme o atual requerimento total de energia estimado para crianças amamentadas saudáveis, de aproximadamente $615 \mathrm{kcal} /$ dia dos 06 aos 08 meses de idade, $686 \mathrm{kcal} /$ dia dos 09 aos 11 meses e $894 \mathrm{kcal} /$ dia dos 12 aos 23 meses (DEWEY et al., 2003).

Para as adequações de ferro e vitamina A foram consideradas as recomendações de FAO/WHO (1998), de 9,3 mg/dia de ferro e para crianças de 6 a 11 meses e 5,8 mg/dia de ferro e de 12 a 23 meses. As recomendações de ferro consideram a biodisponibilidade de 10\%. Em relação à vitamina A, $400 \mu$ gRE são recomendadas para crianças de todas as idades.

\subsection{Processamento e análise dos dados}

Os dados referentes aos inquéritos Recordatórios de 24h foram armazenados em banco de dados desenvolvido no programa Microsoft Office Excel $2007^{\circledR}$.

Para a análise dos dados foi utilizado o programa Statistical Package for the Social Sciences (SPSS), versão 12.01. 


\subsection{Aspectos éticos}

O projeto de pesquisa foi aprovado pelo Comitê de Ética em Pesquisa com Seres Humanos do Hospital Universitário da Universidade Federal do Maranhão ( N $^{\circ}$ 060/10) e pelo Comitê de Ética em Pesquisa da Faculdade de Saúde Pública da Universidade de São Paulo (No 2191/10). (Anexos A e B)

A participação no estudo deu-se mediante a assinatura do Termo de Consentimento Livre e Esclarecido (TCLE) (Anexo C), após concordância do entrevistado, permanecendo com este uma cópia do TCLE.

O projeto recebeu auxílio da Secretaria de Saúde do Estado do Maranhão e da FAPEMA - Fundação de Amparo à Pesquisa e Desenvolvimento Tecnológico do Maranhão por meio do edital PPSUS no 12/2009e do CNPq - Conselho Nacional de Desenvolvimento Científico e Tecnológico por meio da bolsa de produtividade $\mathrm{n}^{\circ}$ 303249/87-0 de SC Szarfarc. 


\section{RESULTADOS E DISCUSSÃO}

O panorama alimentar no Brasil é complexo, com características inerentes a cada região. A extensão territorial do País, a mistura de etnias e culturas, a diversidade dos hábitos alimentares, a estrutura econômico-social, são componentes a serem considerados em relação à alimentação do brasileiro, influenciando na qualidade dessa alimentação, tanto quanto ao acesso propriamente dito ao alimento.

O consumo alimentar adequado e suficiente é um pré-requisito para uma qualidade de vida desejável. São muitos os fatores que interferem para que a segurança alimentar, meta de todos os profissionais de saúde relacionados à nutrição, seja atingida. Determinantes tradicionais como os sociais, econômicos, culturais são acrescidos pela influência da mídia, que por sua vez está atrelada às políticas públicas.

As mudanças que vem se estabelecendo a nível mundial modificam também o panorama de problemas nutricionais que demandam por intervenções públicas diferentes. Exemplificando, a desnutrição cedeu seu espaço para a obesidade e doenças crônicas.

As condições socioeconômicas da população atendida pela ESF no Maranhão reforçam a necessidade de uma atenção maior. Como citado anteriormente, o Estado do Maranhão apresenta uma cobertura de 100\% dos municípios com equipes credenciadas da ESF, sendo que 82,53\% da população maranhense, em 2015 (BRASIL/MS/SAS/DAB), foram atendidas por elas.

Das famílias que participaram do estudo, 96,9\% estavam classificadas nos estratos sociais C, D e E e 54,6\% sobreviviam com menos de $1 / 4$ de salário mínimo per capita. Condições de insegurança alimentar (EBIA) assolavam 70,6\% 
das famílias, sendo 15,6\% na sua forma grave enquanto 65,4\% eram beneficiadas em programas de transferência de renda federal.

A situação social, econômica e política do Nordeste foi retratada no clássico Geografia da Fome, de Josué de Castro, cuja primeira edição data de 1946, onde é traçado o primeiro mapa da fome no País. O Nordeste brasileiro já despontava como área de fome endêmica, com manifestações diretas da deficiência do regime alimentar e também outro tipo de fome, aquela que se apresentava em surtos epidêmicos nos períodos de seca ou estiagem, a fome epidêmica.

O Brasil saiu do Mapa Mundial da Fome em 2014 (FAO, 2014), mas a população permanece vulnerável às carências nutricionais, permanecendo a região Nordeste entre as mais afetadas e dependentes de atenção.

A população de mais baixa renda é aquela que mais sofre o impacto das mudanças contemporâneas da saúde e seus paradoxos, como o enfrentamento concomitante da desnutrição e da obesidade e suas consequências. Assim sendo, compete aos serviços públicos de saúde identificar os riscos de problemas nutricionais e orientar a população visando o controle dos mesmos.

Os lactentes merecem uma atenção especial, tanto pela sua vulnerabilidade como por retratarem no final do período a adequação alimentar da família a qual pertence. Nesse período que eles saem paulatinamente da alimentação láctea e passam a ter na alimentação familiar os determinantes principais do estado nutricional.

A preocupação com o estado nutricional desse grupo e a implantação de intervenções para seu controle datam do final do século passado. A distribuição de ferro através do Programa Nacional de Suplementação de Ferro e a "vacina" da vitamina A distribuída através do Programa Nacional de Suplementação de Vitamina A, ambos instituídos por meio das Portarias $\mathrm{n}^{\circ} 730$ e 729, de 13 de maio de 2005, respectivamente, já estavam presentes no Nordeste desde meados da década de 1990. 
Eles permitiriam supor que lactentes que frequentam Unidades Básicas de Saúde (UBS) teriam a anemia e hipovitaminose A controladas.

No entanto, não é isso que ocorre. A anemia está presente em 25,5\% das crianças nordestinas e a hipovitaminose A em 19\% (PNDS, 2006). No Maranhão, FROTA (2013) encontrou 65\% de lactentes com $\mathrm{Hb}<11,0 \mathrm{~g} / \mathrm{dL}$ e esta classificação, que indica risco grave para a deficiência de ferro (WHO, 2001), também é encontrado nas mulheres em idade fértil (36\%).

Sendo a alimentação o principal determinante de anemia e da hipovitaminose A, entre outras carências nutricionais, é através desse conhecimento que é possível identificar as causas e propor práticas alimentares mais adequadas.

A Tabela 1 apresenta a frequência dos alimentos consumidos na prática alimentar dos lactentes, distribuídos por grupo etário.

Tabela 1 - Distribuição percentual (\%) dos alimentos consumidos pelas crianças, faixa de idade. Maranhão, 2010.

\begin{tabular}{|c|c|c|c|c|}
\hline \multirow{3}{*}{ Alimentos } & \multicolumn{4}{|c|}{ Faixa de idade (meses) } \\
\hline & $\begin{array}{c}6-8 \\
(\mathrm{~N}=64)\end{array}$ & $\begin{array}{c}9-11 \\
(\mathrm{~N}=72)\end{array}$ & $\begin{array}{c}12-17 \\
(\mathrm{~N}=130)\end{array}$ & $\begin{array}{c}18-23 \\
(\mathrm{~N}=135)\end{array}$ \\
\hline & $\%$ & $\%$ & $\%$ & $\%$ \\
\hline Cereais, tubérculos e derivados & 45,3 & 69,4 & 85,4 & 96,3 \\
\hline Arroz & 12,5 & 27,8 & 55,4 & 77,8 \\
\hline Pão, biscoito, macarrão, bolo & 23,4 & 45,8 & 83,8 & 87,4 \\
\hline Batata, mandioca, inhame e derivados & 12,5 & 13,9 & 22,3 & 32,6 \\
\hline Outros (salgadinhos, sanduiches, etc.) & 15,6 & 15,3 & 23,1 & 31,9 \\
\hline $\begin{array}{l}\text { Frutas (banana, laranja, maçã, mamão, } \\
\text { outros) }\end{array}$ & 31,3 & 40,3 & 39,2 & 44,5 \\
\hline $\begin{array}{l}\text { Legumes e verduras (abóbora, cenoura, } \\
\text { chuchu, outros) }\end{array}$ & 28,1 & 36,1 & 40,0 & 45,2 \\
\hline Leite e derivados & 98,4 & 95,8 & 98,4 & 97,0 \\
\hline Leite materno & 20,3 & 5,6 & 9,2 & $\begin{array}{r}5,2 \\
\text { continua }\end{array}$ \\
\hline
\end{tabular}


Tabela 1 - Distribuição percentual (\%) dos alimentos consumidos pelas crianças, faixa de idade. Maranhão, 2010.

\begin{tabular}{|c|c|c|c|c|}
\hline \multirow{3}{*}{ Alimentos } & \multicolumn{4}{|c|}{ Faixa de idade (meses) } \\
\hline & $\begin{array}{c}6-8 \\
(\mathrm{~N}=64)\end{array}$ & $\begin{array}{c}9-11 \\
(\mathrm{~N}=72)\end{array}$ & $\begin{array}{c}12-17 \\
(\mathrm{~N}=130)\end{array}$ & $\begin{array}{c}18-23 \\
(\mathrm{~N}=135)\end{array}$ \\
\hline & $\%$ & $\%$ & $\%$ & $\%$ \\
\hline $\begin{array}{l}\text { Aleitamento misto (leite materno, } \\
\text { mingau, etc.) }\end{array}$ & 53,1 & 59,7 & 46,9 & 30,4 \\
\hline Leite de vaca (mingau, leite puro, etc.) & 25,0 & 30,5 & 42,3 & 61,4 \\
\hline $\begin{array}{l}\text { Carnes (carne bovina, peixe, frango, } \\
\text { outros) }\end{array}$ & 14,1 & 20,8 & 43,1 & 65,9 \\
\hline Leguminosas (todos os tipos) & 7,8 & 18,1 & 21,5 & 37,0 \\
\hline Margarina & 1,6 & 2,8 & 3,8 & 5,2 \\
\hline $\begin{array}{l}\text { Açúcares, doces e bebidas (refresco, café, } \\
\text { refrigerante, outros) }\end{array}$ & 35,9 & 62,5 & 63,8 & 74,8 \\
\hline
\end{tabular}

O leite, em todas as formas de apresentação, foi o primeiro item em frequência de consumo e está presente na alimentação de 97,5\% das crianças. O leite materno esteve presente como único alimento lácteo durante curto período do segundo semestre de vida, sendo já no primeiro semestre compartilhado com o leite de vaca. O mingau é a forma mais frequente com que o leite aparece na alimentação dos lactentes de todas as idades.

Embora o leite de vaca seja fonte de proteína de alto valor biológico e nutrientes essenciais como cálcio, fósforo e vitaminas A, D, B2 e biotina, o aleitamento materno deveria ser continuado até os dois anos de idade, associado à alimentação complementar (WHO, 2002b). Ainda que a inserção do leite de vaca na alimentação das crianças seja uma opção prática, outros fatores desaconselham a substituição do leite materno por ele, como o alto custo da inserção do produto na alimentação das crianças, com impacto na renda familiar (ARAÚJO et al.,2004; REA, 1990) e a associação do leite de vaca na dieta infantil ao risco de anemia em crianças (SPINELLI et al.,2005; OLIVEIRA et al.,2005b; LEVY-COSTA et al.,2004; ASSIS et al.,2004). 
Mesmo não atendendo as recomendações da OMS, as crianças maranhenses têm mantido por muito mais tempo o aleitamento materno quando comparado ao resto do Brasil (BRASIL, 2009c).

Tradicionalmente, no início da alimentação complementar, os itens oferecidos são baseados em frutas amassadas, seguido de tubérculos e legumes que vão sendo gradativamente acrescidos com outros ingredientes como carne, leguminosas e cereais. As papinhas das crianças do Maranhão tinham como ingredientes mais frequentes, legumes, feijão (caldo e grãos), carnes, arroz, macarrão, raízes e tubérculos (batata e macaxeira). A composição da papa salgada varia de acordo com hábitos familiares, tabus alimentares, nível educacional, condição social, entre outros fatores.

Com o aumento da idade há uma ampliação do leque de alimentos e as papas salgadas vão gradualmente sendo substituídas por preparações com texturas mais próximas à presente na alimentação da família. Abóbora, cenoura, chuchu, entre outros legumes referidos, batata, macaxeira, batata-doce, inhame, são ofertados junto a outros alimentos como arroz, feijão e carne, cujas participações aumentam em frequência e quantidade com o crescimento (Tabela 1).

O arroz é o segundo alimento mais frequentemente referido na dieta dos lactentes. Como foi verificado por LEVY et al. (2013) em análise da POF 2008/2009 (IBGE, 2010), o arroz é o alimento mais referido pela população brasileira estando presente em $84 \%$ das dietas.

Chama atenção a participação da farinha de mandioca na alimentação das crianças de todas as idades, mostrando a inserção de um alimento tradicional da região na alimentação das crianças. A farinha de mandioca, “... para o nordestino, ocupa o mesmo lugar que o pão nas outras culturas. É indispensável à mesa do rico e à mesa do pobre...” (QUEIROZ, 2004, p. 35).

Assim como o arroz, o feijão é constituinte importante da alimentação do brasileiro, sendo considerado um alimento básico da nossa mesa. Observamos a 
participação mínima desse alimento entre as crianças estudadas, porém ascendendo com o aumento da idade. A inclusão deste alimento no prato de comida dá-se primeiramente com o caldo e, com o aumento da idade, os grãos vão sendo incorporados. A introdução tardia do feijão, em relação ao arroz, pode estar relacionada à sensação de desconforto após sua ingestão, em decorrência dos níveis de oligossacarídeos rafinose e estaquiose, causadores de flatulência (PHILIPPI, 2008).

Os feijões são a melhor fonte vegetal de ferro. Alem disso, na combinação predileta do brasileiro propicia um aumento do NDPCal\% (Net Protein Calorie Percent) com a combinação da lisina do arroz com a metionina do feijão na refeição contribuindo com uma quantidade energética de proteína utilizável maior.

As carnes fazem parte da alimentação infantil primeiramente com o caldo sem que seja consumida a parte proteica do alimento. A partir dos 9 meses ela já aparece em quantidades mínimas, sempre com uma textura que permita a ingestão pela criança ainda sem dentição completa ou é oferecida à criança para que ela “mame” o pedaço.

Carnes são as melhores fontes de ferro e proteínas de alto valor biológico, além de vitaminas do complexo B e outros minerais, como o zinco. No entanto, os produtos derivados de carnes, como embutidos e produtos enlatados, devem ser evitados em decorrência dos elevados teores de gordura, sal e aditivos químicos.

Não podemos deixar de citar a presença do peixe na alimentação das crianças, sendo $28 \%$ do consumo de carnes desta população. O consumo elevado de peixe é uma característica da população do Norte e Nordeste como evidenciado na POF 2008/2009 (IBGE, 2010), que encontrou um consumo per capita de peixe entre 10 a 20 Kg/ano no Maranhão, contrastando com o consumo per capita de apenas 2 Kg/ano nas regiões Sul e Centro-Oeste e nos Estados de São Paulo e Minas Gerais. Entre as crianças brasileiras esse alimento nem é referido, como observado por 
SPINELLI et al. (2005) em investigação da prevalência de anemia nas cinco regiões do Brasil.

Uma alimentação baseada em carboidratos e proteínas pode melhorar indicadores antropométricos nas crianças, visto que promove o aumento de peso e altura satisfatórios, porém a associação ao consumo inadequado de outros alimentos fontes de vitaminas e minerais pode predispor a carências nutricionais múltiplas ou específicas, como anemia e hipovitaminose A, bem como predeterminar doenças causadas pelos excessos de disponibilidade de energia, como obesidade e diabetes.

Nos últimos anos as políticas de saúde voltadas à promoção de práticas saudáveis de alimentação têm estimulado o consumo de vários tipos de frutas, verduras e legumes visando uma alimentação saudável e diversificada. Entretanto, no Maranhão apenas $40 \%$ das crianças de todas as idades consumiram frutas e $39 \%$ verduras e/ou legumes, embora seja observada uma tendência de aumento com a idade.

Consumo mais frequente de frutas e verduras foi descrito na PNDS (2006) onde a presença diária desses itens alimentares em lactentes variou de 63\% em crianças de 6 a 11 meses de idade, 57\% entre 12 e 17 meses e 65\% entre 18 e 23 meses. Entretanto, LEVY et al. (2013) em análise da POF 2008/2009 (IBGE, 2010), verificaram a menor presença de frutas (16\%) e verduras (16\%) na alimentação da população brasileira. Pode-se supor que a menor frequência observada entre as crianças maranhenses possa ser um reflexo do quadro encontrado para a população adulta brasileira.

O consumo inadequado de frutas, verduras e legumes é um dos cinco fatores associados ao risco de doenças crônicas não transmissíveis, como as cardiovasculares e o câncer (WHO, 2002c). Monitorar o consumo destes alimentos em todas as fases do ciclo da vida e os aspectos socioculturais envolvidos nesta relação é importante para diminuir o risco para desnutrições a elas atribuídas. 
O consumo de açúcar simples está associado ao aumento da obesidade e outras doenças crônicas não transmissíveis. Açúcares simples não devem participar da alimentação das crianças menores de 2 anos. No entanto, como mostra a Tabela 1 , a inserção desse grupo de alimentos é considerável e aumenta rapidamente com o aumento da idade, o que significa que ele tem presença maciça na dieta da família. Encontramos a participação ativa do açúcar na alimentação das crianças. Os mingaus são adoçados e é elevado o consumo de café, refrescos artificiais e refrigerantes, nos quais o único nutriente presente é o açúcar.

Em conformidade às orientações para hábitos de alimentação saudável às crianças menores de 2 anos, além do veto ao consumo de açúcares simples, alimentos que no processo de produção utilizam uma gama de ingredientes como sal, óleos e gorduras, aditivos alimentares, entre outros, alguns dos quais adicionados para aumentar a duração desses produtos, não devem ser consumidos. Nesse sentido destaca-se um consumo importante entre as crianças maranhenses de miojo, biscoito doce, cheese-tudo, salgadinhos, tortas, refrescos, refrigerantes, entre outros produtos industrializados (Tabela 1).

Reconhecendo a magnitude dos distúrbios nutricionais nas crianças e as doenças a eles relacionadas, o MS vem se empenhando no propósito de erradicar estes agravos. As ações de saúde têm como objetivo melhorar as condições de alimentação, nutrição e saúde das populações, através de vigilância alimentar e nutricional, prevenção e cuidados integrais aos agravos relacionados à alimentação e nutrição.

Os guias alimentares vêm em consonância desses objetivos orientar práticas alimentares saudáveis, sendo instrumentos da maior relevância tanto para a identificação de problemas nutricionais como para orientação de indivíduos e/ou populações a respeito de riscos decorrentes da inadequação da dieta. Os diversos guias nacionais vêm considerando a transição da alimentação que assola o País, fruto do desenvolvimento, quer seja da indústria alimentícia, quer seja da influência da mídia, fomento à agricultura e a agroindústria ou políticas de exportação de alimentos. Embora a alimentação no Brasil (arroz, feijão e carnes) seja mantida a 
incorporação de alimentos altamente industrializados vem aumentando, mesmo entre os lactentes. As categorizações propostas para os alimentos pelos diversos guias nacionais, por vezes, podem dificultar a avaliação do consumo bem como o entendimento pela população, especialmente quando vários alimentos são ingredientes de preparações culinárias, podendo constituir um impasse na melhora das condições de alimentação, nutrição e saúde da população.

Jarbas Barbosa, presidente da Agência Nacional de Vigilância Sanitária, defende mudanças na embalagem dos alimentos visando facilitar para o consumidor a identificação de produtos com alto teor de sal, açúcar ou gorduras (FORMENTI, 2015). O Ministério da Saúde recomenda a adoção de uma dieta rica em frutas, verduras e legumes em quantidades moderadas dos três elementos como é referido no Guia Alimentar para a População Brasileira (BRASIL, 2014).

O Guia Alimentar para Crianças Menores de 2 anos (BRASIL, 2005) orienta práticas alimentares saudáveis, incentivando o aleitamento materno e a introdução oportuna e adequada da alimentação complementar, no intuito de garantir segurança alimentar para esta população e atender ao direito humano à alimentação adequada.

A Pirâmide Alimentar Infantil, representação gráfica do Guia, esquematiza o consumo dos alimentos de acordo com os conceitos de variedade, moderação e proporcionalidade, visando uma alimentação harmônica, adequada, quantitativa e qualitativamente equilibrada. A alimentação das crianças deve garantir o consumo de alimentos variados, nas porções recomendadas, de acordo com o nível que o grupo alimentar se encontra na Pirâmide. Os grupos de alimentos foram estabelecidos conforme presença de macro e micronutrientes nos alimentos e as porções foram estimadas em função do valor energético total da dieta e da energia de cada grupo alimentar, respeitando a forma usual de consumo do alimento (BRASIL, 2005).

A alimentação complementar oportuna e adequada, introduzida no momento correto, além de fornecer os nutrientes necessários à demanda do 
crescimento, é uma oportunidade para expor as crianças a uma alimentação variada, contribuindo na formação de hábitos saudáveis. O Quadro 2 apresenta o número de porções per capita por grupos de alimentos que orienta a prática alimentar das crianças.

Tabela 2 - Número de porções per capita por grupos de alimentos, segundo proporção de consumidores e faixa etária. Maranhão, 2010.

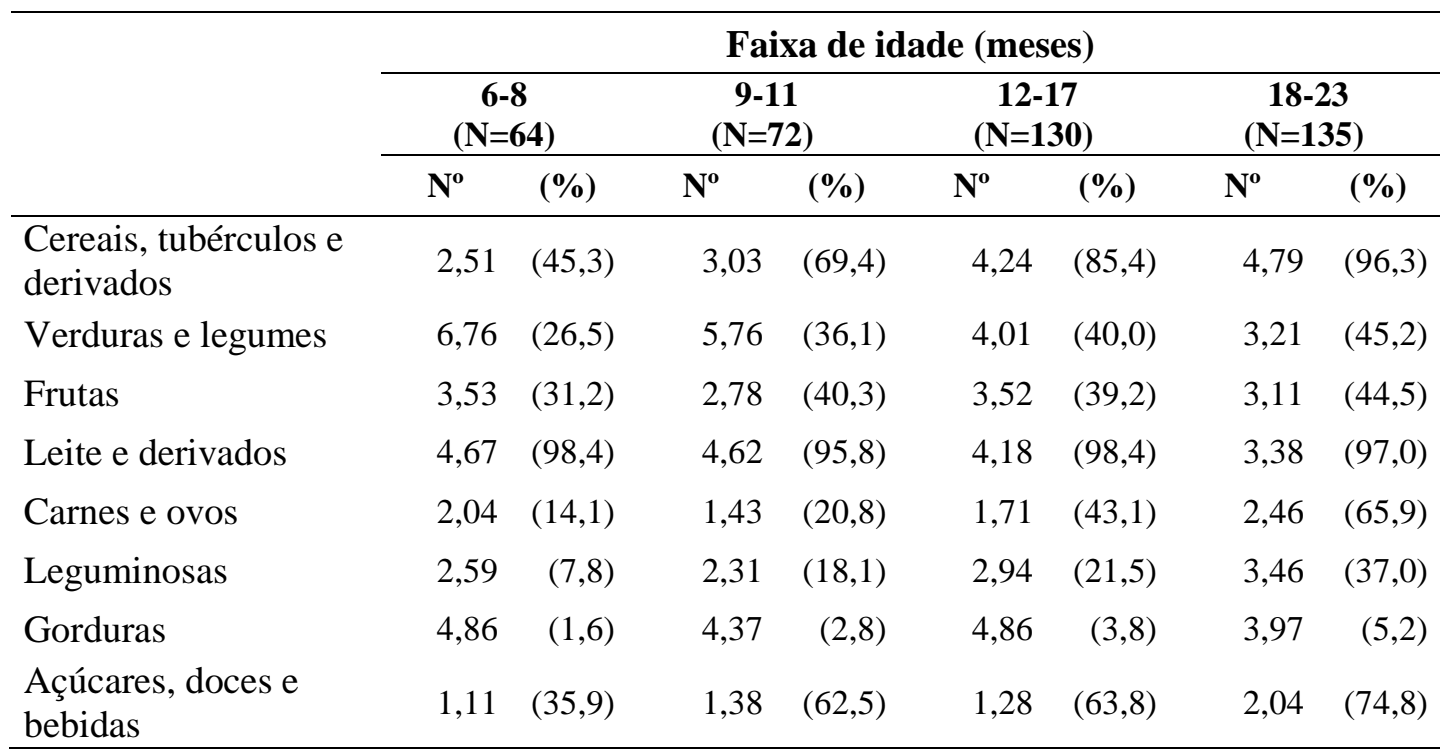

À exceção do grupo de açúcares, houve adequação de frequência entre as crianças que ingerem os alimentos específicos de cada grupo. No entanto, a proporção de crianças que os ingere está longe de atingir a totalidade delas, com exceção dos alimentos lácteos.

O grupo dos leites e derivados apresentou consumo per capita maior que o esperado em todas as faixas de idade. É preconizado o consumo de três porções deste grupo para crianças de até 2 anos (Quadro 2). Valores de até 75\% acima do recomendado foram encontrados, em decorrência do leite muitas vezes substituir e/ou complementar o almoço e/ou jantar. Com isso há um detrimento à oportunidade 
de inserção de novos alimentos reduzindo a possibilidade de percepção a novos sabores, podendo impactar no posterior comportamento alimentar do lactente, inclusive expondo a criança à anemia que está fortemente associada à elevada ingestão de leite de vaca (SPINELLI et al.,2005; OLIVEIRA et al.,2005b; LEVYCOSTA et al.,2004; ASSIS et al.,2004).

Com a mesma concepção, a participação não recomendada do grupo de açúcares, doces e bebidas submete a criança a doenças que envolvem o consumo excessivo de alimentos altamente energéticos como a obesidade e suas consequências.

O grupo dos cereais, tubérculos e derivados apresentou consumo per capita menor que o esperado para a maioria das crianças. Para este grupo é determinado o consumo de três porções para crianças de 6 a 12 meses de idade e cinco porções para as de 12 e 24 meses (Quadro 2). Alimentos ricos em carboidratos complexos deveriam estar presentes em quantidades maiores, pois além de aumentar a densidade energética, apresentam na sua composição proteínas, vitaminas do complexo B, minerais, ácidos graxos essenciais e fibras alimentares, além de serem veículos da fortificação obrigatória de ferro e ácido fólico, neste caso nas farinhas e trigo e milho.

Em relação ao consumo de feijão, a recomendação de duas porções deste grupo foi alcançada por todas as crianças consumidoras. Considerando o contexto da alta prevalência de anemia nessa população, esse resultado é relevante, pois o feijão é uma importante fonte do mineral.

O consumo determinado na Pirâmide de pelo menos três porções diárias de verduras e legumes e três a quatro de frutas de acordo com a faixa etária (Quadro 2), não foi almejado pela maior parte das crianças. Entre as crianças consumidoras foi verificado o dobro das recomendações para o grupo das verduras e legumes entre 6 e 11 meses de idade, decrescendo a partir daí, porém mantendo-se dentro dos padrões adequados. Para o grupo das frutas, observou-se atenção às recomendações, igualmente entre 6 e 11 meses, evidenciando a questão cultural que envolve a 
introdução da alimentação complementar, quando a oferta de alimentos tidos como saudáveis são priorizados.

O grupo de óleos e gorduras teve frequência expressiva na alimentação das crianças consumidoras, atingindo valores 100\% superiores aos recomendados. Quantidades excessivas deste grupo de alimento estão relacionadas ao aumento das doenças crônicas não transmissíveis, sendo orientada a inclusão parcimoniosa na alimentação em todo o ciclo da vida.

Há que destacar, mais uma vez, a baixa frequência com que as carnes, as leguminosas e principalmente as frutas, legumes e verduras são referidos pelas mães.

Com intuito de ampliar os conhecimentos sobre a saúde da população brasileira, o Instituto Brasileiro de Geografia e Estatística - IBGE, elaborou em convênio com o Ministério da Saúde a Pesquisa Nacional de Saúde - PNS 2013: percepção do estado de saúde, estilos de vida e doenças crônicas (IBGE, 2013). O desempenho do sistema nacional de saúde, as condições de saúde da população brasileira e a vigilância das doenças crônicas não transmissíveis e fatores de risco associados foram os eixos de base da PNS. A forte associação dessas enfermidades a fatores de riscos conhecidos como o excesso de peso, níveis elevados de colesterol, baixo consumo de frutas e verduras e sedentarismo, justifica o monitoramento desses agravos no intuito de subsidiar políticas de saúde.

A PNS considera marcadores de padrão saudável da alimentação o consumo recomendado de frutas, verduras e legumes, equivalente ao consumo de 85\% das porções diárias recomendadas para esses alimentos e o consumo regular de feijão. O consumo de refrigerantes, carnes com excesso de gordura, consumo de sal e de alimentos doces, como bolos, tortas, chocolates, balas, biscoitos ou bolachas doces, são elencados à condição de marcadores de padrão não saudáveis, tão importante seu papel no desenvolvimento de doenças.

Na Tabela 3 é apresentada a frequência de alimentos segundo proposta da PNS, por faixa de idade. 
Tabela 3 - Distribuição de frequência (\%) dos alimentos segundo marcadores da alimentação, por faixa etária. Maranhão, 2010.

\begin{tabular}{|c|c|c|c|c|}
\hline \multirow{3}{*}{ Marcador } & \multicolumn{4}{|c|}{ Faixa de idade (meses) } \\
\hline & 6-8 & $9-11$ & $12-17$ & $18-23$ \\
\hline & $\%$ & $\%$ & $\%$ & $\%$ \\
\hline $\begin{array}{l}\text { Marcadores de padrão saudável de } \\
\text { alimentação }\end{array}$ & 13,3 & 14,0 & 14,8 & 16,1 \\
\hline $\begin{array}{l}\text { Marcadores de padrão não saudável de } \\
\text { alimentação }\end{array}$ & 6,2 & 9,9 & 11,7 & 16,7 \\
\hline
\end{tabular}

Observamos que o consumo de alimentos recomendados aumenta lentamente com a idade, enquanto o aumento entre os marcadores de alimentação não saudável ocorre mais intensamente. Essa situação é preocupante visto ser este quadro retrato da alimentação familiar com todos os riscos dele decorrente.

Com metodologia diferente, todavia com o mesmo propósito, o Guia Alimentar para a População Brasileira (BRASIL, 2014), foi lançado pelo Ministério da Saúde com intuito de ser utilizado por todos os brasileiros, profissionais de saúde, educadores, pelas pessoas em suas casas, nas escolas, centros comunitários e demais lugares que promovam a saúde e prevenção de doenças. O Guia recomenda a utilização parcimoniosa ou mesmo a não utilização de alguns alimentos que conforme o tipo de processamento empregado na produção condiciona de forma negativa seu perfil de atendimento às necessidades nutricionais.

De acordo com o Guia, alimentos in natura ou minimamente processados são obtidos diretamente de plantas ou animais, como frutas, verduras e legumes, ovos, leite, sem que tenham sofrido quaisquer alterações ou sofreram alterações mínimas, como legumes e verduras congelados e leite pasteurizado. Devem constituir a maior parte, cerca de 85\%, da alimentação dos brasileiros; Óleos, gorduras, açúcar e sal devem ser consumidos em pequenas quantidades ao temperar alimentos para preparações culinárias; Alimentos processados são os fabricados pela indústria a partir de alimentos in natura, com adição de sal ou açúcar ou outras 
substâncias utilizadas para melhorar o sabor e aumentar o tempo de prateleira. A utilização de alimentos processados como queijos, pães, frutas em calda, é limitada ao uso como parte de refeições a base de alimentos in natura ou minimamente processados; e alimentos ultraprocessados como refrigerantes, biscoitos, salgadinhos, macarrão instantâneo, entre muitos outros devem ser evitados. Em geral, esses são alimentos produzidos em grandes indústrias, com adição de muitos ingredientes nocivos ao consumo humano.

Na Tabela 4 é apresentada a frequência de alimentos segundo proposta de processamento empregado, por faixa de idade.

Tabela 4 - Participação relativa (\%) dos alimentos segundo categoria de processamento empregado na produção, por faixa etária. Maranhão, 2010.

\begin{tabular}{lrrrr}
\hline \multirow{2}{*}{ Grupos de alimentos } & \multicolumn{4}{c}{ Faixa de idade (meses) } \\
\cline { 2 - 5 } & $\mathbf{6 - 8}$ & $\mathbf{9 - 1 1}$ & $\mathbf{1 2 - 1 7}$ & $\mathbf{1 8 - 2 3}$ \\
\cline { 2 - 5 } & $\mathbf{\%}$ & $\mathbf{\%}$ & $\mathbf{\%}$ & $\mathbf{\%}$ \\
\hline In natura e minimamente processados & 66,2 & 62,5 & 64,9 & 61,6 \\
Óleos, gorduras, sal e açúcar & 5,5 & 9,3 & 7,3 & 8,2 \\
Processados & 22,1 & 18,5 & 16,3 & 14,4 \\
Ultraprocessados & 6,2 & 9,6 & 11,4 & 15,9 \\
\hline Total & 100,0 & 100,0 & 100,0 & 100,0 \\
\hline
\end{tabular}

Embora longe dos 85\% recomendados, os alimentos considerados adequados têm a maior frequência de consumo entre as crianças de todas as idades. Entretanto, verifica-se que com o aumento da idade ocorre o aumento concomitante de alimentos ultraprocessados e diminuição dos processados. Esta tendência na alimentação vem sendo rechaçada de forma notória em publicações científicas, guias alimentares e políticas de saúde, em decorrência de inúmeros malefícios que acarretam à saúde da população.

LEVY-COSTA et al. (2012) justificaram o baixo consumo de alimentos considerados seguros e o alto consumo de alimentos considerados danosos à saúde 
quando verificaram o efeito da renda familiar sobre a aquisição de alimentos. Analisando a participação de carnes, frutas, verduras e legumes, verificaram que o consumo diminui de forma uniforme nas classes de menores rendimentos e o inverso acontece com o açúcar que tem o consumo aumentando nessas condições. Com o aumento dos rendimentos, diminui também o consumo de arroz e aumenta a participação de pães, biscoitos e refrigerantes na alimentação. Neste contexto, crianças mais pobres estão mais expostas às deficiências nutricionais, pois os alimentos mais prestigiados são aqueles mais deficientes em micronutrientes e ricos em calorias.

O fornecimento adequado de energia em uma dieta variada e equilibrada pode assegurar o suprimento de nutrientes suficientes para atender à demanda nutricional em todas as fases da vida. Por sua vez, a inadequação alimentar favorece situações de risco nutricional, contribuindo para o surgimento de processos carenciais múltiplos ou específicos.

O consumo de cereais, raízes e tubérculos como principal fonte de energia está bem estabelecido nas recomendações atuais, assim como a orientação de que sejam consumidos na sua forma natural. As formas integrais desses alimentos garantem o teor de vitaminas, minerais, ácidos graxos e fibras alimentares, reduzidos quando do beneficiamento desses alimentos.

A participação no valor calórico total de energia proveniente do grupo de açúcares, doces e bebidas é considerada elevada e inadequada, visto que não é desejável a presença desses itens na alimentação de crianças menores de 2 anos (BRASIL, 2005) (Tabela 5). 
Tabela 5 - Participação relativa (\%) dos grupos de alimentos na disponibilidade total de energia, segundo faixa etária. Maranhão, 2010.

\begin{tabular}{|c|c|c|c|c|}
\hline \multirow{3}{*}{ Grupos de alimentos } & \multicolumn{4}{|c|}{ Faixa de idade (meses) } \\
\hline & 6-8 & 9-11 & $12-17$ & $18-23$ \\
\hline & $\%$ & $\%$ & $\%$ & $\%$ \\
\hline Leite e derivados & 75,1 & 64,5 & 52,6 & 38,5 \\
\hline Cereais, tubérculos e derivados & 11,7 & 19,0 & 28,8 & 33,8 \\
\hline Arroz & 1,8 & 3,2 & 7,9 & 11,0 \\
\hline Pão, biscoito, macarrão, bolo & 3,5 & 10,3 & 12,1 & 10,0 \\
\hline Batata, mandioca e derivados & 1,6 & 2,9 & 5,3 & 6,3 \\
\hline Outros & 4,8 & 2,6 & 3,5 & 6,5 \\
\hline Açúcar, doces e bebidas & 3,0 & 5,8 & 4,8 & 8,2 \\
\hline Frutas & 5,3 & 4,8 & 5,1 & 4,7 \\
\hline Legumes e verduras & 2,0 & 2,0 & 1,4 & 1,1 \\
\hline Leguminosas & 0,4 & 1,0 & 1,4 & 2,5 \\
\hline Carnes e ovos & 2,3 & 2,3 & 5,1 & 10,3 \\
\hline Gordura & 0,4 & 0,5 & 0,7 & 0,8 \\
\hline Total & 100,0 & 100,0 & 100,0 & 100,0 \\
\hline Média per capita de calorias (kcal) & 735 & 824 & 938 & 1022 \\
\hline Recomendação (DEWEY et al., 2003) & 615 & 686 & 894 & 894 \\
\hline
\end{tabular}

Dados do Estudo Multicêntrico de Consumo Alimentar (GALEAZZI et al., 1997) realizado nas cidades de Salvador, Outro Preto, Goiânia, São Paulo e Curitiba mostraram uma grande participação de cereais, tubérculos e derivados na dieta das crianças. Na capital Salvador, a participação destes grupos de alimentos variou de 22,6 \% entre 6 e 12 meses de idade a 29,0\% entre 12 e 24 meses. Até os 11 meses de idade a frequência de consumo desses alimentos nas crianças estudadas é inferior ao encontrado para Salvador, porém aumenta expressivamente com o aumento da idade.

SZARFARC et al. (1988) observaram inadequação de energia em crianças menores de 5 anos no município de São Paulo de 4\% em crianças de 6 a 12 meses e 37,3\% entre 12 e 24 meses. Em estudo realizado em um município da grande 
São Paulo, MODESTO, et al. (2007) verificaram que poucas crianças apresentaram consumo de energia inferir às recomendações, com 7,8\% em crianças de 6 a 8 meses e 8,3\% entre 9 e 12 meses. Com características regionais mais próximas, foi observado por FIDELIS et al. (2007) em crianças menores de 5 anos no Estado de Pernambuco, prevalência de inadequação de 26,5\% em crianças de 6 a 11 meses e 41,4\% entre 12 e 36 meses, superiores ao encontrado entre as crianças maranhenses, onde a adequação de energia foi de 95,4\%.

As crianças brasileiras menores de 2 anos em geral ingerem quantidades adequadas de calorias, porém a reduzida variedade dos alimentos introduzidos pode levar a inadequações no fornecimento de micronutrientes favorecendo situações de risco nutricional e contribuindo para o surgimento de processos carenciais (OLIVEIRA et al., 2005a; SOUZA et al., 1999).

De acordo com o apresentado até o momento, observamos que o consumo alimentar das crianças do Maranhão é fortemente lácteo, rico em açúcares simples, reduzido em frutas, verduras e legumes, o que pode contribuir para o surgimento de carências nutricionais, como a anemia e a hipovitaminose A.

A OMS define anemia como um estado em que os valores de hemoglobina apresentam-se inferiores aos considerados normais para idade, sexo e estado fisiológico (WHO, 2001).

A Tabela 6 apresenta a contribuição de ferro dos alimentos fontes desse mineral na prática alimentar dos lactentes. 
Tabela 6 - Participação relativa (\%) dos principais alimentos fonte de ferro no fornecimento do nutriente, segundo faixa etária. Maranhão, 2010.

\begin{tabular}{lrrrr}
\hline \multirow{2}{*}{ Grupos de alimentos } & \multicolumn{4}{c}{ Faixa de idade (meses) } \\
\cline { 2 - 5 } & $\mathbf{6 - 8}$ & $\mathbf{9 - 1 1}$ & $\mathbf{1 2 - 1 7}$ & $\mathbf{1 8 - 2 3}$ \\
\cline { 2 - 5 } & $\mathbf{\%}$ & $\mathbf{\%}$ & $\mathbf{\%}$ & $\mathbf{\%}$ \\
\hline Carnes & 2,4 & 2,4 & 6,2 & 15,8 \\
Fortificados (Pão, biscoito, macarrão, bolo) & 16,5 & 33,2 & 29,1 & 33,5 \\
Leguminosas & 1,7 & 2,9 & 4,7 & 7,9 \\
\hline Média per capita de ferro (mg) & $\mathbf{4 , 3}$ & $\mathbf{5 , 0}$ & $\mathbf{5 , 3}$ & $\mathbf{6 , 3}$ \\
\hline Recomendação (mg) (FAO/WHO (1998) & $\mathbf{9 , 3}$ & $\mathbf{9 , 3}$ & $\mathbf{5 , 8}$ & $\mathbf{5 , 8}$ \\
\hline
\end{tabular}

O fator nutricional é condicional, visto que a deficiência não ocorre somente pela quantidade insuficiente do mineral na alimentação, mas também pela baixa biodisponibilidade do ferro presente no prato alimentar. São duas as formas de ferro dietético, o ferro heme e o ferro não-heme. O ferro heme presente nas carnes apresenta taxa de absorção mais elevada, em torno de 25\%. O ferro não-heme, presente nos alimentos de origem vegetal tem sua absorção alterada pela composição da refeição, por fatores que podem estimular ou inibir essa absorção. São dois os mais facilitadores de absorção do ferro não heme, carnes e vitamina $C$, variando sua absorção entre 3,0 e 7,5\% (MONSEN e BALINTFY, 1982).

Leguminosas são também excelentes fontes de ferro, no entanto a biodisponibilidade deste nutriente é baixa nesses alimentos.

A melhora observada no perfil de atendimento da recomendação de ferro com o aumento da idade, além do aumento de consumo de carnes, está associada à fortificação das farinhas de trigo e milho com ferro (BRASIL, 2002). Também há que considerar que a velocidade relativa de crescimento diminui com a idade e o consumo de alimentos complementares aumenta, justificando o atendimento das recomendações. 
Entre os lactentes maranhenses foram identificados 97\% de inadequação do consumo de ferro em crianças entre 9 e 11 meses, valores superiores aos observados por SZARFARC et al. (1988) no município de São Paulo, que encontrou inadequação de 60\% em crianças de 6 a 12 meses e 48,5\% entre 12 e 24 meses. Em estudo realizado por FIDELIS et al. (2007) em Pernambuco, foi encontrado prevalência de inadequação de ferro na dieta de 65,0\% em crianças de 6 a 11 meses e 23,7\% entre 12 e 36 meses. Dados do Estudo Multicêntrico de Consumo Alimentar (GALEAZZI et al., 1997), demonstram que na capital Salvador a inadequação foi de $47,8 \%$ entre 6 e 12 meses e 32,2\% entre 13 e 24 meses.

A implantação do PNSF, presente no Maranhão desde 1994, permitiria supor que o controle da deficiência de ferro estivesse alcançado. No entanto, como apresentado por FROTA (2013), a prevalência da anemia ocorre em proporção considerada grave entre a população de lactentes aqui estudadas. A diminuição concomitante da recomendação de ferro e da prevalência da anemia com a idade é função da desaceleração de crescimento encontrada a partir do primeiro ano de vida junto com a inserção da criança na alimentação familiar.

Embora a anemia seja um tema amplamente estudado, seus determinantes conhecidos e estratégias de prevenção e tratamento definidas e operacionalizadas, como a fortificação de farinhas e a suplementação medicamentosa profilática, os índices continuam em ascensão. MONTEIRO, et al. (1987), estudando anemia no município de São Paulo, observaram prevalência de 53,7\% em crianças de 6 a 12 meses e 58,1\% entre 12 e 24 meses. Mais recente e após a implantação das estratégias de combate à anemia, SPINELLI et al. (2005) em estudo realizado nas cinco regiões brasileiras, verificaram anemia em $70,4 \%$ das crianças da região Sudeste e 65,9\% das crianças nordestinas com idade entre 6 a 12 meses. Entre a população de estudo, ou seja, entre os lactentes maranhenses atendidos pela ESF FROTA (2013) encontrou 65\%.

Ainda entre esta população, FROTA (2013) verificou a baixa proporção de referências ao recebimento do sulfato ferroso (21,5\%) o que poderia justificar a alta prevalência de crianças anêmicas. Era esperado que na ocasião da inserção das 
crianças aos padrões de alimentação da família, que ocorre ao redor dos 18 meses de idade, houvesse melhora nos níveis de inadequação desse mineral em virtude do aumento da participação de alimentos fortificados com ferro na dieta. Entretanto, a alta prevalência de mulheres anêmicas (36\%) permite a suposição de que a efetividade da fortificação das farinhas a partir da RDC 344/2002 (BRASIL, 2002), não está alcançando o proposto por este método de combate à anemia.

Ao lado da anemia ferropriva, que se mantém entre os grandes chamarizes das políticas de saúde, a deficiência de vitamina A ainda assume graves proporções, não obstante as intervenções implantadas para seu controle. A deficiência por período prolongado pode causa alterações relacionadas às funções fisiológicas do organismo humano (visão, crescimento, reprodução, hematopoiese e imunidade).

A identificação da situação alimentar e nutricional da população, com destaque à ingestões inadequadas da vitamina $\mathrm{A}$ ao longo de todo o ciclo de vida continua sendo prioritário para embasar as ações de vigilância alimentar e nutricional.

A Tabela 7 apresenta a contribuição dos principais alimentos fontes de vitamina A no fornecimento do nutriente na alimentação das crianças, por faixa de idade.

Tabela 7 - Participação relativa (\%) dos principais alimentos fonte de vitamina A no fornecimento do nutriente, segundo faixa etária. Maranhão, 2010.

\begin{tabular}{lrrrr}
\hline \multirow{2}{*}{ Grupos de alimentos } & \multicolumn{4}{c}{ Faixa de idade (meses) } \\
\cline { 2 - 5 } & $\mathbf{6 - 8}$ & $\mathbf{9 - 1 1}$ & $\mathbf{1 2 - 1 7}$ & $\mathbf{1 8 - 2 3}$ \\
\cline { 2 - 5 } & $\mathbf{\%}$ & $\mathbf{\%}$ & $\mathbf{\%}$ & $\mathbf{\%}$ \\
\hline Leite e derivados & 90,1 & 85,7 & 79,0 & 46,2 \\
Frutas, legumes e verduras & 6,9 & 9,1 & 12,5 & 3,1 \\
\hline Média per capita de vitamina A ( $\mu$ gRE) & $\mathbf{3 8 2 , 4}$ & $\mathbf{3 7 4 , 8}$ & $\mathbf{3 6 0 , 2}$ & $\mathbf{4 6 2 , 6}$ \\
\hline Recomendação ( $\boldsymbol{\mu g R E )}$ (FAO/WHO (1998) & $\mathbf{4 0 0 , 0}$ & $\mathbf{4 0 0 , 0}$ & $\mathbf{4 0 0 , 0}$ & $\mathbf{4 0 0 , 0}$ \\
\hline
\end{tabular}


Como observado, o leite é praticamente o único veículo de vitamina A na alimentação das crianças. A grande quantidade consumida deste alimento garante o atendimento às recomendações nutricionais (Figura 1).

Em relação às médias per capita encontradas, verificamos valor acima do recomendado entre as crianças de 18 a 23 meses. Entretanto, quando observado o percentual de adequação, conclui-se que a ingestão de vitamina A apresenta valores adequados apenas para $23,7 \%$ das crianças estudadas. Este resultado pode ser explicado pela grande variabilidade de ingestão (DP \pm 932 ), provavelmente em decorrência da introdução de novos alimentos e ainda o incremento de vísceras na alimentação infantil.

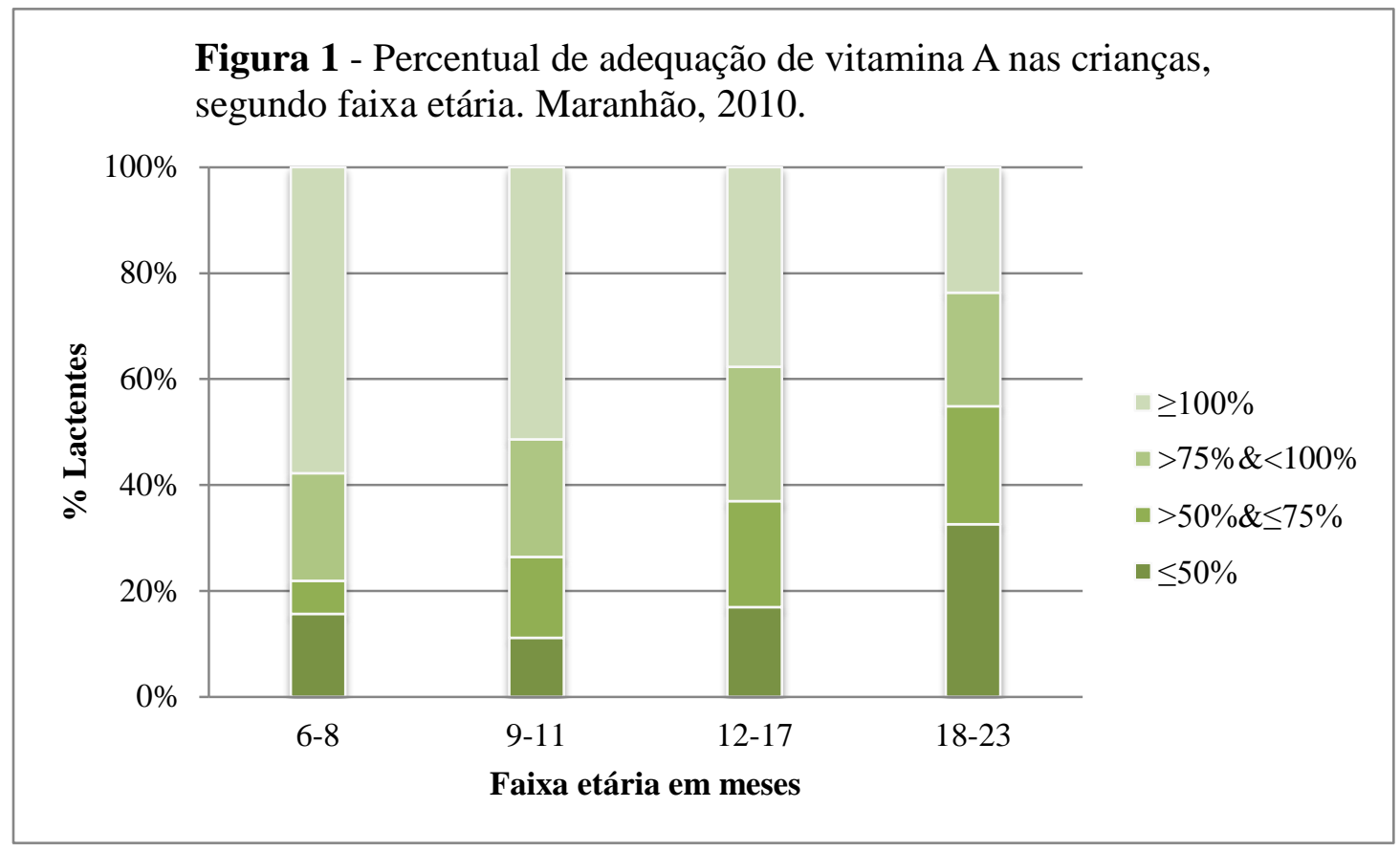

PRADO, et al. (1995) observaram em crianças de 6 a 72 meses de áreas rurais do semiárido baiano, inadequação de consumo de vitamina A na dieta de 58,4\% de crianças menores de 12 meses e 45,5\% entre 12 e 23 meses de idade. FIDELIS et al. (2007) verificaram em crianças menores de 5 anos no Estado de 
Pernambuco, prevalência de inadequação de 44\% em crianças de 12 a 36 meses. Os resultados encontrados permitem supor que a vulnerabilidade social e econômica da população maranhense possa ter influência sobre o quadro encontrado.

Para BERLINGUER (1987) doenças evitáveis, mas não evitadas, criam sobrecarga em todos os níveis de atenção à saúde, do ambulatório ao hospital mais especializado, porém o aumento da rede assistencial sem intervir na causa é utopia. A assistência aos doentes deve estar interligada à proteção da saúde.

O esforço para que isso ocorra está presente na realidade nacional. O acesso a serviços de saúde através da ESF significa um avanço nas possibilidades de melhor situação de saúde para a população.

Com relação a alimentação, a orientação oferecida a grupos vulneráveis para que a segurança alimentar seja atingida faz parte das atividades das UBS. No entanto, há que considerar que esta somente será atingida se for entendido que a alimentação segura para o lactente é a mesma segura para a criança e a família. Como foi observado neste estudo, o lactente é privilegiado com alimentos marcadores de padrões saudáveis da alimentação que vão diminuindo com o passar dos meses. Seria, pois, necessário conscientizar as famílias para o uso rotineiro desses produtos garantindo a todos o fornecimento de minerais e vitaminas em quantidades adequadas.

Os guias que vem sendo utilizados no Brasil ratificam essa afirmação. Vale destacar o Guia Alimentar para a População Brasileira o qual considera os riscos decorrentes do consumo de itens alimentares como açúcar, sal e gorduras, mas orientando seu uso moderado dentro das preparações domésticas. Chama atenção a orientação do guia para o consumo de água, que embora reconhecida como indispensável por todos os profissionais de saúde, está presente pela primeira vez numa orientação para a prática alimentar (BRASIL, 2014). 
Com relação à deficiência de ferro, a substituição dos compostos utilizados na fortificação das farinhas por outros de maior poder de absorção está sendo cogitada pelo MS.

Por sua vez a substituição do sulfato ferroso do PNSF pelo "sache" com multiminerais e vitaminas é bem-vindo. No entanto, enquanto isso não ocorre a possibilidade de substituição do sulfato ferroso utilizado no programa pelo Fechel ${ }^{\circledR}$ cuja eficiência e eficácia são comprovados (DIAS et al.,2013; ARRAVAL et al.,2002; SZARFARC et al.,2000), ou outro composto de elevada biodisponilidade, seria oportuno. O "Projeto Vivaleite", programa estadual criado pelo Governo do Estado de São Paulo, utiliza o ferro quelato na fortificação do leite que é distribuído em todo o Estado para crianças de 6 meses a 6 anos de famílias com renda de até $1 / 4$ de salário mínimo per capita (SÃO PAULO, 2000).

Uma vez que o PNSF ou o "sache" são intervenções restritas aos lactentes, seria importante destacar e preparar adequadamente, ao lado de mudanças na fortificação das farinhas, as equipes da ESF.

A ESF sendo um modelo de atenção que beneficia as populações mais dependentes de ações do governo tem um papel relevante que vai de identificar a prática alimentar de grupos populacionais vulneráveis a orientar possíveis mudanças respeitando a cultura local e as possibilidades econômicas.

A capacitação dos profissionais envolvidos na ESF com temas que valorizem a área da alimentação e nutrição e que especialmente façam parte das atividades de rotina de trabalho desses profissionais parece ser um caminho para que a segurança alimentar seja atingida pela população, em consonância aos princípios do SUS e ao esperado para a Atenção Básica. 


\section{CONCLUSÕES}

O estudo da "Prática Alimentar de Lactentes Atendidos na Estratégia Saúde da Família no Maranhão” permitiu as seguintes conclusões:

- A alimentação das crianças de 6 a 23 meses maranhenses tem algumas características que as diferenciam do resto do Brasil. O aleitamento materno está presente no dia alimentar se mantendo mesmo com a introdução do leite de vaca. O mingau - leite, açúcar e espessante - é ingerido mesmo no almoço e jantar em detrimento de outros itens alimentares e com alguma frequência como componente único da refeição.

- A frequência com que os grupos de alimentos estão presentes no dia alimentar varia de forma importante. A totalidade das crianças tem o leite com a frequência recomendada ou maior. Os cereais, as carnes e as leguminosas têm sua presença e frequências aumentadas com a idade, mostrando a tendência de inserção das crianças na rotina alimentar familiar. O mesmo ocorre em relação ao açúcar que vai rapidamente aumentando a frequência e quantidade. O inverso se vê em relação aos chamados alimentos marcadores de padrões saudáveis; frutas, verduras e legumes são privilégios das lactentes.

- A presença de alimentos marcadores de padrões saudáveis da alimentação pouco se modifica com a idade em contraste com os marcadores de padrão alimentar não saudável que tem sua presença na dieta praticamente triplicada.

- O Guia Alimentar para a População Brasileira mostra a manutenção em nível abaixo do adequado para alimentos in natura, mas confirmando o visto pela Pesquisa Nacional de Saúde aumento considerável das referências a alimentos ultraprocessados.

- Verificou-se que o consumo médio de energia dos lactentes é adequado destacando-se o aumento com a idade de participação do arroz, farináceos tubérculos, leguminosas e carnes no dia alimentar. 
- O aumento importante e indesejável do açúcar foi também observado, enquanto legumes e verduras tem seu consumo gradativamente diminuído à metade.

- A pequena presença de fontes e verduras justifica sua quase ausência como veículo da vitamina A, que tem sua recomendação atendida graças a presença de leite entre a totalidade das crianças.

- O ferro tem sua recomendação atendida pelos derivados do trigo fortificado, sendo nítido o aumento de frequência e quantidade de feijão e carnes no dia alimentar. 


\section{REFERÊNCIAS}

ANTUNES, M. M. L.; SICHIERI, R.; SALLES-COSTA, R. Consumo alimentar de crianças menores de três anos residentes em área de alta prevalência de insegurança alimentar domiciliar. Cad Saude Publica, v. 26, n. 8, p. 1642-50, 2010.

ARAÚJO, M. D. F.; DEL FIACO, A.; PIMENTEL, L. S.; SCHMITZ, B. D. A. S. Custo e economia da prática do aleitamento materno para a família. Rev. bras. saúde matern. infant, v. 4, n. 2, p. 135-141, 2004.

ARRAVAL, S. R.; SZARFARC, S. C. Consumo alimentar e anemia por deficiência de ferro. In: IV Forum Internacional da Alimentação Fora do Lar, 2002, São Paulo, 2002.

ASSIS, A. M. O.; GAUDENZI, E. N.; GOMES, G.; RIBEIRO, R. D. C.; SZARFARC, S. C.; SOUZA, S. B. D. Níveis de hemoglobina, aleitamento materno e regime alimentar no primeiro ano de vida. Rev Saúde Pública, v. 38, n. 4, p. 543-51, 2004.

BARRETO, S. M.; PINHEIRO, A. R. D. O.; SICHIERI, R.; MONTEIRO, C. A.; SCHIMIDT, M. I.; LOTUFO, P. et al. Análise da estratégia global para alimentação, atividade física e saúde, da Organização Mundial da Saúde.Epidemiologia e serviços de saúde, v. 14, n. 1, p. 41-68, 2005.

BATISTA FILHO, M.; DE SOUZA, A.; MIGLIOLI, T. C.; DOS SANTOS, M. C. Anemia e obesidade: um paradoxo da transição nutricional brasileira Anemia and obesity: a paradox of the nutritional transition in Brazil. Cad. Saúde Pública, v. 24, n. Sup 2, p. S247-S257, 2008.

BERLINGUER, G. Medicina e política. In: Saúde em debate. Hucitec, 1987.

BERNARDI, J. L. D.; JORDÃO, R. E.; BARROS FILHO, A. A. Alimentação complementar de lactentes em uma cidade desenvolvida no contexto de um país em desenvolvimento. Rev Panam Salud Publica, v. 26, n. 5, p. 405-11, 2009.

BRASIL. AGÊNCIA NACIONAL DE VIGILÂNCIA SANITÁRIA (ANVISA). Resolução RDC $\mathrm{n}^{\circ}$ 344, de 13 de dezembro de 2002. Regulamento técnico para fortificação das farinhas de trigo e das farinhas de milho com ferro e ácido fólico. Diário Oficial da União, Brasília, DF, 18 dez. 2002. Disponível em: http://www.anvisa.gov.br/alimentos/farinha.htm. Acesso em 26 fev 2014. 
BRASIL. Ministério da Saúde. Departamento de Atenção Básica. Coordenação geral da Política de Alimentação e Nutrição. Compromisso social para a redução da anemia por carência de ferro no Brasil. Brasília, DF, 1999. Disponível em: http://189.28.128.100/nutricao/docs/ferro/compromisso_social_reducao_anemia.pdf Acesso em: 23 fev. 2014.

BRASIL. Ministério da Saúde. Pesquisa Nacional de Demografia e Saúde da Criança e da Mulher - PNDS 2006: dimensões do processo reprodutivo e da saúde da criança. Brasília, DF, 2009a.

BRASIL. Ministério da Saúde. Secretaria de Assistência à Saúde. Departamento de Atenção Básica - DAB. Teto, credenciamento e implantação das estratégias de Agentes Comunitários de Saúde, Saúde da Família e Saúde Bucal. Disponível em: http://dab.saude.gov.br/portaldab/historico_cobertura_sf.php Acesso em: 02 jun. 2015.

BRASIL. Ministério da Saúde. Secretaria de Atenção à Saúde. Departamento de Atenção Básica. Saúde da criança: nutrição infantil: aleitamento materno e alimentação complementar (Série A. Normas e Manuais Técnicos). Brasília, DF, 2009b.

BRASIL. Ministério da Saúde. Secretaria de Atenção à Saúde. Departamento de Ações Programáticas e Estratégicas. II Pesquisa de Prevalência de Aleitamento Materno nas Captais Brasileiras e Distrito Federal. Brasília, DF, 2009c.

BRASIL. Ministério da Saúde. Secretaria de Atenção à Saúde. Departamento de Atenção Básica. Dez passos para uma alimentação saudável: guia alimentar para crianças menores de dois anos: um guia para o profissional da saúde na atenção básica. (Série A. Normas e Manuais Técnicos). Brasília, DF, 2013.

BRASIL. Ministério da Saúde. Secretaria de Atenção à Saúde. Departamento de Atenção Básica. Política Nacional de Alimentação e Nutrição (Série B. Textos Básicos de Saúde). Brasília, DF, 2012a.

BRASIL. Ministério da Saúde. Secretaria de Atenção à Saúde. Departamento de Atenção Básica. Política Nacional de Atenção Básica (Série E. Legislação em Saúde). Brasília, DF, 2012b.

BRASIL. Ministério da Saúde. Secretaria de Atenção à Saúde. Departamento de Atenção Básica. Guia alimentar para a população brasileira / Ministério da Saúde, Secretaria de Atenção à Saúde, Departamento de Atenção Básica. - 2. ed. - Brasília : Ministério da Saúde, 2014.

BRASIL. Ministério da Saúde/Organização Pan-Americana da Saúde. Guia alimentar para crianças menores de 2 anos. (Serie A. Normas e Manuais Técnicos). Brasília, DF, 2005. 
BRASIL. Presidência da República. Relatório Nacional de Acompanhamento dos Objetivos de Desenvolvimento do Milênio. Brasília, DF, 2007.

CAETANO, M. C.; ORTIZ, T. T. O.; SILVA, S. D.; SOUZA, F. D.; SARNI, R. O. S. Alimentação complementar: práticas inadequadas em lactentes. J. Pediatr, v. 86, n. 3, p. 196-201, 2010.

CASTRO J. Geografia da fome: dilema brasileiro - pão ou aço. 10a ed. Rio de Janeiro: Antares Achiamé; 1980.

CONSEA. II Conferência Nacional de Segurança Alimentar e Nutricional Relatório Final. Centro de Convenções de Pernambuco, Olinda, PE, 17 a 20 de março de 2004.

CORRÊA, E. N.; CORSO, A. C. T.; MOREIRA, E. A. M.; KAZAPI, I. A. M. Alimentação complementar e características maternas de crianças menores de dois anos de idade em Florianópolis (SC). Rev Paul Pediatr, v. 27, n. 3, p. 258-64, 2009.

COUTINHO, J. G.; GENTIL, P. C.; TORAL, N. A desnutrição e obesidade no Brasil: o enfrentamento com base na agenda única da nutrição Malnutrition and obesity in Brazil: dealing with the problem through. Cad. Saúde Pública, v. 24, n. Sup 2, p. S332-S340, 2008.

DECLARAÇÃO Universal dos Direitos Humanos. Adotada e proclamada pela resolução 217 A (III) da Assembléia Geral das Nações Unidas em 10 de dezembro de 1948. Disponível em: http://unesdoc.unesco.org/images/0013/001394/139423por.pdf Acesso em: 28 Nov. 2010.

DEWEY, K. G.; BROWN, K. H. Update on technical issues concerning complementary feeding of young children in developing countries and implications for intervention programs. Food and Nutrition Bulletin-United Nations University-, v. 24, n. 1, p. 5-28, 2003.

DIAS, A. C. P.; SZARFARC, S. C. Intervenção nutricional alternativa no controle da anemia em crianças e mães. Espaço para a Saúde (Online), v. 14, p. 1-13, 2013.

FARIAS JÚNIOR, G.; OSÓRIO, M. M. Padrão alimentar de crianças menores de cinco anos. Rev. nutr, v. 18, n. 6, p. 793-802, 2005.

FIDELIS, C. M. F.; OSÓRIO, M. M. Consumo alimentar de macro e micronutrientes de crianças menores de 5 anos no Estado de Pernambuco, Brasil. Rev. bras. saúde matern. infant, v. 7, n. 1, p. 63-74, 2007.

FORMENTI, L. Anvisa quer que rótulo informe alto teor de sal, gordura e açúcar. $\mathbf{O}$ Estado de São Paulo. São Paulo, 30 jul: 2015. Caderno Metrópole, p. A16. 
FROTA, M. T. B. A. Prevalência e fatores associados à anemia em crianças e mulheres atendidas pela estratégia de Saúde da Família no Maranhão. 2013. Tese (Doutorado em Nutrição em Saúde Pública) - Faculdade de Saúde Pública, Universidade de São Paulo, São Paulo. Disponível em: http://www.teses.usp.br/teses/disponiveis/6/6138/tde-08042013-101924/ Acesso em: 20 nov. 2013.

GALEAZZI, M. A. M.; DOMENE, S. M. A.; SICHIERI, R. Estudo multicêntrico sobre consumo alimentar. Cadernos de debate, v. 47, n. sSuppl, 1997.

INSTITUTO BRASILEIRO DE GEOGRAFIA E ESTATÍSTICA (IBGE). Pesquisa de Orçamentos Familiares 2008-2009: despesas, rendimentos e condições de vida. Rio de Janeiro: IBGE, 2010.

INSTITUTO BRASILEIRO DE GEOGRAFIA E ESTATÍSTICA (IBGE). Censo Demográfico 2010: IBGE - Maranhão. (12 Recenseamento Geral do Brasil, 2010c). Disponível em: http://www.ibge.gov.br/estadosat/perfil.php?sigla=ma Acesso em: 02 fev. 2015.

INSTITUTO BRASILEIRO DE GEOGRAFIA E ESTATÍSTICA (IBGE). Pesquisa de Orçamentos Familiares 2008/2009 - Tabelas de Composição Nutricional dos Alimentos Consumidos no Brasil. 1 ed. Rio de Janeiro, RJ, 2011.

INSTITUTO BRASILEIRO DE GEOGRAFIA E ESTATÍSTICA (IBGE). Pesquisa Nacional de Saúde 2013 - Percepção de Estado de Saúde, Estilo de Vida e Doenças Crônicas. Brasil, Grandes Regiões e Unidades da Federação. Disponível em: ftp://ftp.ibge.gov.br/PNS/2013/pns2013.pdf Acesso em: 27 abr. 2015.

INSTITUTO BRASILEIRO DE GEOGRAFIA E ESTATÍSTICA (IBGE). Segurança alimentar: 2004. Rio de Janeiro, RJ, 2006.

Levy, R. B.; Claro, R. M.; Mondini, L.; Sichieri, R.; Monteiro, C. A. Distribuição regional e socioeconômica da disponibilidade domiciliar de alimentos no Brasil em 2008-2009. Rev Saúde Pública, v. 46, n. 1, p. 6-15, 2012.

LEVY, R. B.; SICHIERI, R. Alimentos mais consumidos no Brasil: Inquérito nacional de alimentação 2008-2009. Rev Saúde Pública, v. 47, n. 1 Supl, p. 190S9S, 2013.

LEVY-COSTA, R. B.; MONTEIRO, C. A. Consumo de leite de vaca e anemia na infância no Município de São Paulo. Rev Saúde Pública, v. 38, n. 6, p. 797-803, 2004.

MIGLIOLI, T. C.; BRITO, A. M.; LIRA, P. I. C.; FIGUEROA, J. N. Anemia no binômio mãe-filho no Estado de Pernambuco, Brasil Mother-child anemia in the State of Pernambuco, Brazil.Cad Saude Publica, v. 26, n. 9, p. 1807-20, 2010. 
MODESTO, S. P.; DEVINCENZI, M. U.; SIGULEM, D. M. Práticas alimentares e estado nutricional de crianças no segundo semestre de vida atendidas na rede pública de saúde. Rev. nutr, v. 20, n. 4, p. 405-415, 2007.

MONSEN, E. R.; BALINTFY, J. L. Calculating dietary iron bioavailability: refinement and computerization. Journal of the American Dietetic Association, v. 80, n. 4, p. 307-311, 1982.

MONTEIRO, C. A.; MONDINI, L.; COSTA, Renata B. L. Mudanças na composição e adequação nutricional da dieta familiar nas áreas metropolitanas do Brasil (19881996). Rev Saúde Pública, v. 34, n. 3, p. 251-8, 2000.

MONTEIRO, C. A.; SZARFARC, S. C. Estudo das condições de saúde das crianças no município de São Paulo, SP (Brasil), 1984-1985. Rev Saúde Pública, v. 21, n. 3, p. 225-60, 1987.

OLIVEIRA, L. P. M.; ASSIS, A. M. O.; PINHEIRO, S. M. C.; PRADO, M. S.; BARRETO, M. L. Alimentação complementar nos primeiros dois anos de vida. Rev. nutr, v. 18, n. 4, p. 459-469, 2005a.

OLIVEIRA, M. A.; OSÓRIO, M. M. Consumo de leite de vaca e anemia ferropriva na infância. J Pediatr, v. 81, n. 5, p. 361-7, 2005b.

PHILIPPI, S. T. Pirâmide dos alimentos: fundamentos básicos da nutrição. In: Guias de nutrição e alimentação. Manole, 2008.

PORTELA, G. Z.; RIBEIRO, J. M. A sustentabilidade econômico-financeira da Estratégia Saúde da Família em municípios de grande porte. Ciência \& Saúde Coletiva, v. 16, n. 3, p. 1719-1732, 2011.

PRADO, M. S.; ASSIS, A. M. O.; MARTINS, M. C.; NAZARÉ, M. D. P. A.; REZENDE, I. F. B.; CONCEIÇÃO, M. E. P. Hipovitaminose A em crianças de áreas rurais do semi-árido baiano. Revista de Saúde Pública, v. 29, n. 4, p. 295-300, 1995.

QUEIROZ, R. O Não Me Deixes: suas histórias e sua cozinha. 2a ed. São Paulo: Arx, 2004.

REA, M. F. Substitutos do leite materno: passado e presente. Revista de Saúde Pública, v. 24, n. 3, p. 241-249, 1990.

ROTENBERG, S.; DE VARGAS, S. Práticas alimentares e o cuidado da saúde: da alimentação da criança à alimentação da família. Rev. bras. saúde matern. infant, v. 4, n. 1, p. 85-94, 2004.

SÃO PAULO (Estado). Decreto n. 45.014 de 28 de junho de 2000. Altera o Decreto n. 44.569 de 22 de dezembro de 1999, que instituiu o Projeto Estadual do Leite 
"Vivaleite". Disponível em: http://governosp.jusbrasil.com.br/legislacao/142490/decreto-45014-00. Acesso em: 31 jul. 2015.

SEGALL-CORRÊA, A. M.; PÉREZ-ESCAMILLA, R.; MARANHA, L. K.; SAMPAIO, M. F. A.; YUYAMA, L.; ALENCAR, F. et al. Acompanhamento e avaliação da segurança alimentar de famílias brasileiras: validação de metodologia e de instrumento de coleta de informação. Urbano/rural. Relatório técnico: versão preliminar. Brasília (DF): Ministério da Saúde: Organização Pan-Americana da Saúde, 2003.

SILVA, S. C. L.; BATISTA FILHO, M.; MIGLIOLI, T. C. Prevalência e fatores de risco de anemia em mães e filhos no Estado de Pernambuco. Rev. bras. epidemiol, v. 11, n. 2, p. 266-277, 2008.

SOUZA, S. B.; SZARFARC, S. C.; SOUZA, J. M. P. Prática alimentar no primeiro ano de vida, em crianças atendidas em centros de saúde escola do município de São Paulo.Rev Nutr, v. 12, n. 2, p. 167-74, 1999.

SPINELLI, M. G. N.; MARCHIONI, D. M. L.; SOUZA, J. M. P.; SOUZA, S. D.; SZARFARC, S. C. Fatores de risco para anemia em crianças de 6 a 12 meses no Brasil. Rev Panam Salud Publica, v. 17, n. 2, p. 84-91, 2005.

SZARFARC S. C.; MONTEIRO, C. A.; MEYER, M.; TUDISCO, E. S.; REIS, I. M. Estudo das condições de saúde das crianças do município de São Paulo, SP (Brasil), 1984/1985 X consumo alimentar. Rev Saúde Pública, v. 22, n. 4, p. 266-72,1988.

SZARFARC, S. C.; MARCHIONI, D. M. L.; NAME, J. J.; GUERRA, J. F.; ARRAVAL, S. R.; PHILIPPI, S. T. Controle da anemia através do uso intermitente de ferro bis glicina incorporado às refeições. In: XII CONGRESO DA SBAN, 2000, BUENOS AIRES. LIBRO DE RESUNEBES DE TRABAJOS LIBRES, 2000. p. 304-304.

TABACCHI, G; WIJNHOVEN, T. M. A.; BRANCA, F.; ROMÁN-VINAS, B.; RIBAS-BARBA L.; NGO, J.; GARCIA-ÁLVAREZ, A.; SERRA-MAJEM L. How is the adequacy of micronutrient intake assessed across Europe? A systematic literature review. British Journal of Nutrition, v. 101, n. S2, p. S29-S36, 2009.

WORLD HEALTH ORGANIZATION. Complementary feeding of young children in developing countries: a review of current scientific knowledge. Geneva: WHO, 1998.

WORLD HEALTH ORGANIZATION. Complementary feeding. Report of the global consultation: summary of guinding principles. Geneva: WHO, 2002a.

WORLD HEALTH ORGANIZATION. Global Strategy for Infant and Young Child Feeding. Geneva: WHO, 2003. 
WORLD HEALTH ORGANIZATION. Iron deficiency anaemia: assessment, prevention and control: a guide for programme managers. Geneva: WHO, 2001.

WORLD HEALTH ORGANIZATION. The optimal duration of exclusive breastfeeding: a systematic review. Geneva: WHO, 2002b.

WORLD HEALTH ORGANIZATION. The world health report 2002: reducing risks, promoting healthy life. Geneva: WHO, 2002c. 


\section{ANEXOS}

ANEXO I - Parecer consubstanciado do Comitê de Ética em Pesquisa do Hospital Universitário da Universidade Federal do Maranhão.

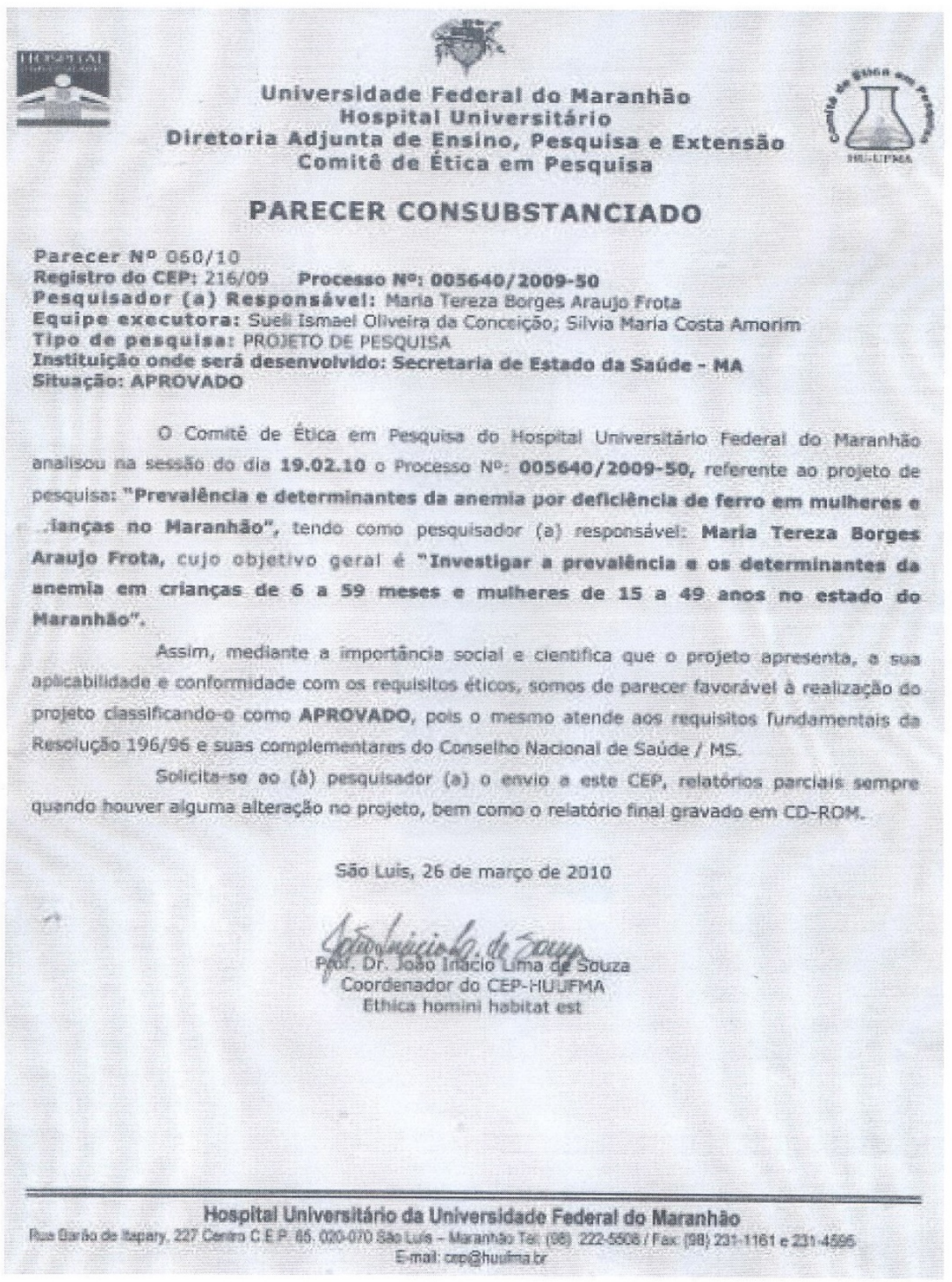




\section{ANEXO II - Ofício do Comitê de Ética em Pesquisa da Faculdade de Saúde Pública} da Universidade de São Paulo.

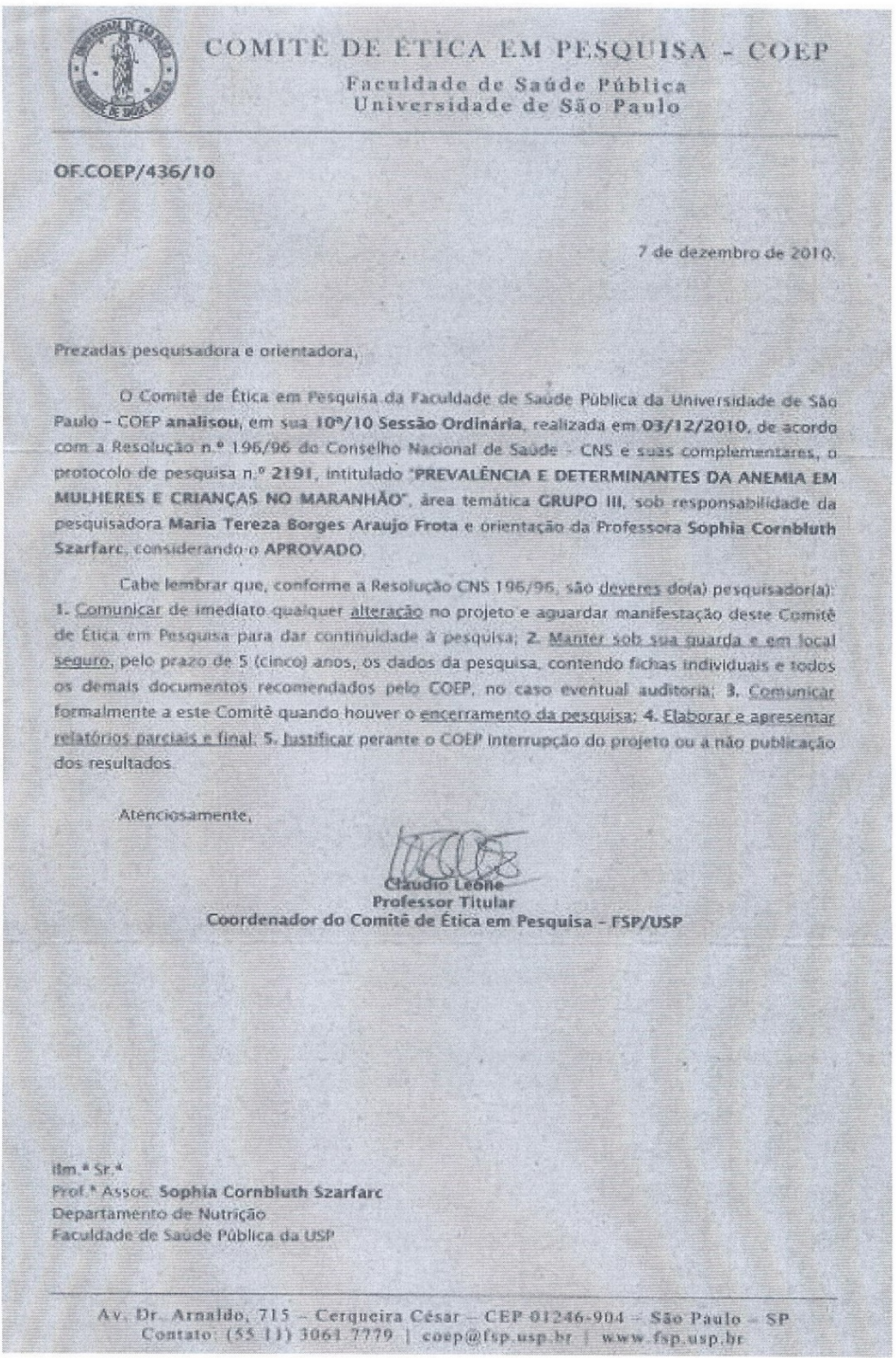




\section{ANEXO III - Termo de Consentimento Livre e Esclarecido.}

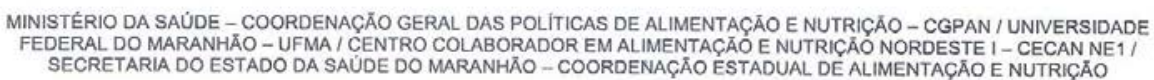

\section{TERMO DE CONSENTIMENTO LIVRE ESCLARECIDO}

\section{NQUES}

\section{Título: Prevalência e Fatores Associados à Anemia em Mulheres e Crianças no Maranhão}

\section{A) Proposta:}

Você está sendo convidado a participar de um estudo que a professora da Universidade Federal do Maranhão, Maria Tereza Borges Araujo Frota está realizando, com a finalidade de avaliar a prevalência da anemia entre crianças de 6 a 59 meses e mulheres de 15 a 49 anos de idade no estado do Maranhão, bem como analisar os indicadores sociais e nutricionais que podem influenciar a ocorrência dessa doença.

\section{B) Procedimento}

Se você concordar em participar, as seguintes coisas acontecerão:

1. Você responderá a um questionário com informaçôes sobre aspectos socioeconômicos e demográficos, estilo de vida, clínicos e nutricionais.

2. Você será submetido a uma avaliação do estado nutricional que constará de medidas corporais de peso, altura e circunferência da cintura e do quadril para identificar seu estado nutricional. Isto levará cerca de 20 minutos.

3. Você também terá sangue coletado da ponta do seu dedo com uma micro lanceta, que servirá para investigar se você está com anemia.

4. Você também poderá receber orientação sobre alimentação saudável e alimentos ricos em ferro, para prevenir a anemia.

\section{C) Riscos e Desconforto}

Os riscos para o desenvolvimento de complicações médicas são muito pequenos. A coleta de sangue poderá causar algum desconforto, que durará poucos segundos.

Caso você ache inapropriada alguma das questões que constam do questionário ou the produza sentimentos indesejáveis, poderá interromper a entrevista a qualquer momento caso.

\section{D) Benefícios}

O teste de anemia irá auxiliar na investigação do seu estado de saúde. Isto poderá trazer beneficio direto para você ao participar deste estudo.

\section{E) Custo}

Você não será cobrado por qualquer dos procedimentos realizados no estudo.

\section{F) Reembolso}

Você não será reembolsado por participar deste estudo.

\section{G) Confiabilidade dos dados}

A participação em projetos de pesquisa pode resultar em perda de privacidade, entretanto, procedimentos serão tomados pelos responsáveis por este estudo, no intuito de proteger a confidencialidade das informações que você irá fornecer. As informações scrão codificadas e mantidas em local reservado o tempo todo. Após o término deste estudo, as informações serão transcritas dos questionários para arquivos em computador os quais serão mantidos arquivados em local reservado. Os dados deste estudo poderão ser discutidos com pesquisadores de outras instituições, mas nenhuma identificação será fornecida. 


\section{H) Tratamento e compensação por injúria}

Se você sofrer qualquer injúria como resultado da sua participação neste estudo, ou se acreditar que não tenha sido tratado razoavelmente, poderá entrar em contato com o pesquisador responsável por este estudo, Prof. Msc Maria Tereza Borges Araujo Frota, no departamento de Ciências Fisiológicas da Universidade Federal do Maranhão ou pelo telefone (98) 3301-8531. Entretanto, a Universidade Federal do Maranhão não prevê nenhuma forma de compensação financeira por possíveis injúrias. Para qualquer outra informação deverá contatar o médico responsável.

\section{I) Questões}

Se você tiver alguma pergunta a respeito dos seus direitos como participante deste estudo de pesquisa, você deverá entrar em contato com Prof. Dr. João Inácio Lima de Souza, coordenador do Comitêde Ética para Pesquisa em Seres Humanos no Hospital Universitário Presidente Dutra, localizado na RuaBarão de Itapary, 227 - São Luís - MA, ou pelo telefone 2109.1250.

\section{J) Consentimento}

A PARTICIPAÇÃo EM PESQUISA É VOLUNTÁRIA. Você tem o direito de não concordar em participar ou mesmo de retirar-se do estudo em qualquer momento, sem riscos para o seu tratamento médico. Se você desejar e concordar em participar, deve assinar na linha abaixo deste documento em duas vias. Uma delas, com a assinatura do pesquisador responsável, ficará em seu poder.

Nome do paciente:

$\mathrm{CPF} / \mathrm{ID}:$

Assinatura do paciente ou responsável: Data:

Assinatura do pesquisador responsável: 


\section{ANEXO IV - Questionário da Pesquisa.}

MINISTÉRIO DA SAÚDE - COORDENAÇÃO GERAL DAS POLITICAS DE ALIMENTAÇÃO E NUTRIÇÃO - CGPAN / UNIVERSIDADE FEDERAL DO MARANHĀO - UFMA / CENTRO COLABORADOR EM ALIMENTAÇĀO E NUTRIÇÃO NORDESTI I- CECAN NE1 / SECRETARIA DO ESTADO DA SAÚDE DO MARANHĀO - COORDENAÇĀO ESTADUAL DE ALIMENTAÇĀO NUTRIÇÃO

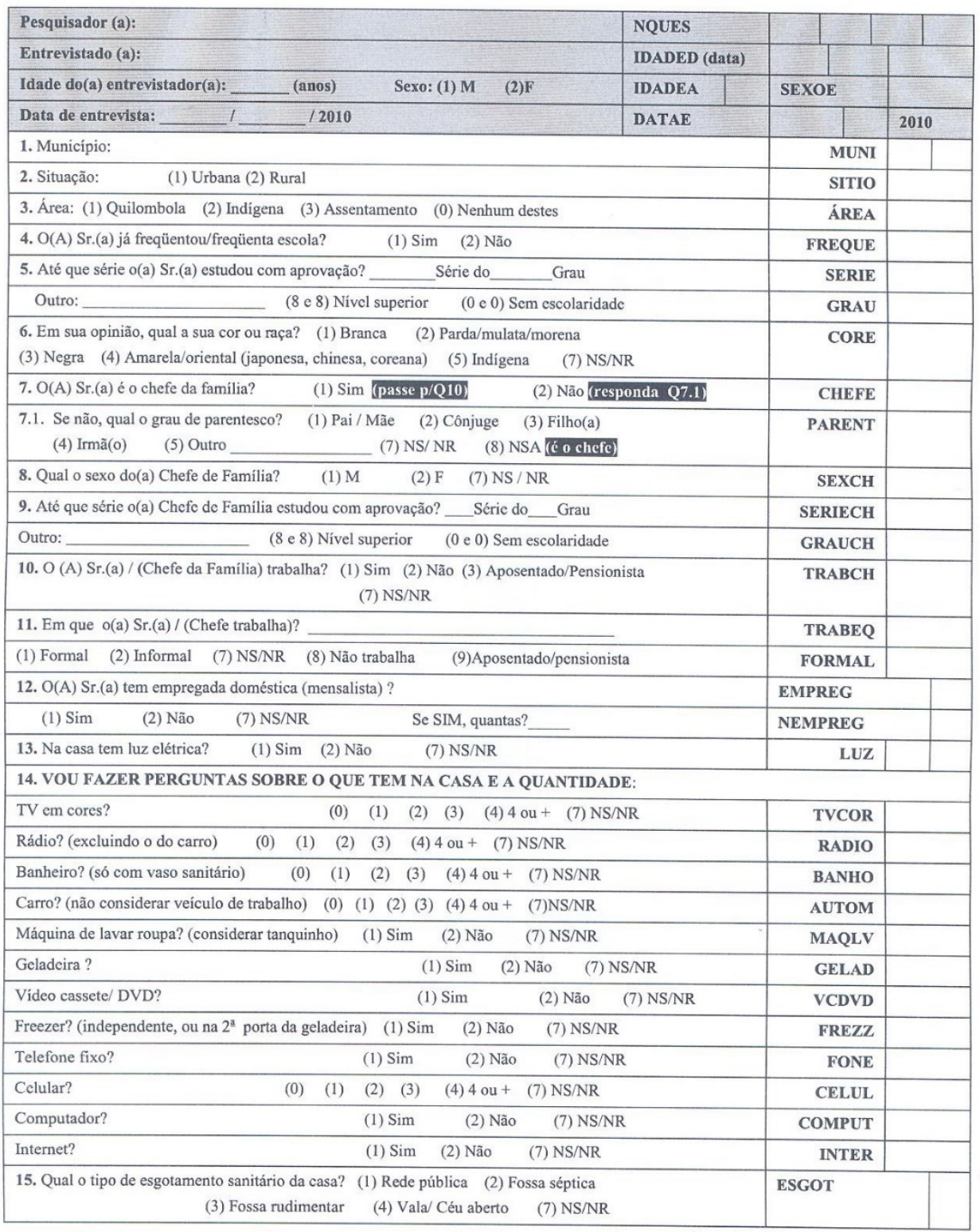




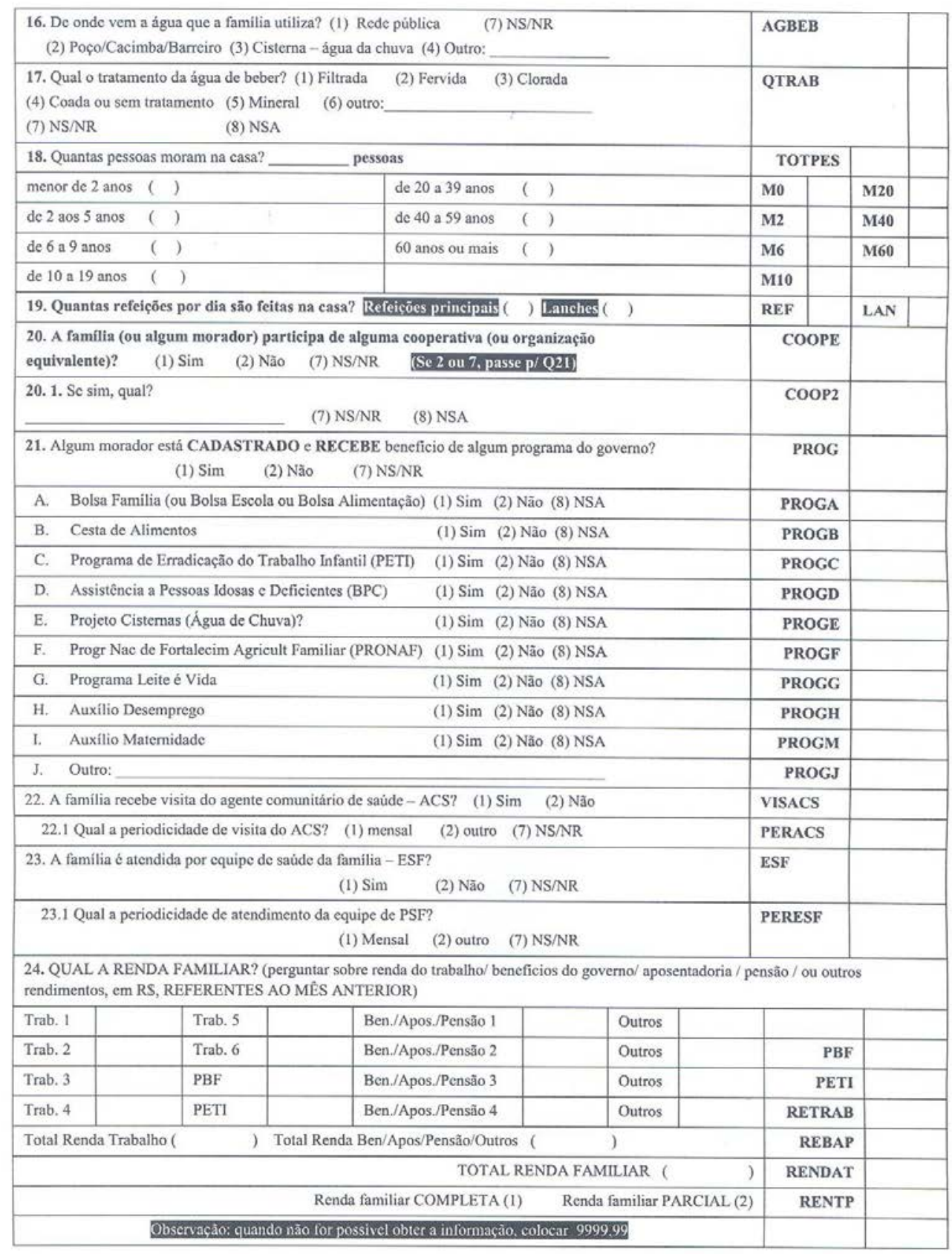




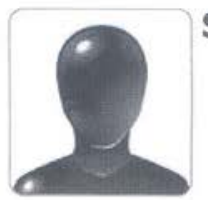

\section{Sophia Cornbluth Szarfarc}

Endereço para acessar este CV: http://lattes.enpq.br/0210155032002852

Última atualizaçăo do curriculo em 17/03/2014

possui graduação em Química pela Universidade de São Paulo (1963), graduação em Química pela Universidade de São Paulo (1963), mestrado em Nutrição pela Universidade de São Paulo (1970) e doutorado em Nutrição pela Universidade de São Paulo (1973). Atualmente é professor adjunto, aposentada atuando no Departamento de Nutrição da Faculdade de Saúde Pública da Universidade de São Paulo. Tem experiência na área de Nutrição, com ênfase em Análise Nutricional de População, atuando principalmente nos seguintes temas: anemia, lactentes, saude publica, aleitamento materno e gestantes. (Texto informado pelo autor)

\section{Identificação}

$\begin{array}{ll}\text { Nome } & \text { Sophia Cornbluth Szarfarc } \\ \text { Nome em citaçöes bibliográficas } & \text { SZARFARC, S. C.;SZARFARC, SOPHIA CORNBUTH }\end{array}$

\section{Endereço}

Endereço Profissional
Universidade de São Paulo, Faculdade de Saúde Pública, Departamento de
AV.DR. ARNALDO 715
CERQUEIRA CESAR
O1246-904 - Sao Paulo, SP - Brasil
Telefone: (11) 30667701
Ramal: 241
Fax: (11) 30667701

\section{Formação acadêmica/titulação}

\begin{tabular}{ll}
\hline 1971 - 1973 & Doutorado em Nutrição. \\
Universidade de São Paulo, USP, Brasil. \\
Titulo: ANEMIA FERROPRIVA EM PASTURIENTES E RECEM-NASCIDOS DE UM \\
GRUPO POPULACIONAL. DE BAIXO NIVEL SOCIO-ECONOMICO DE SAO PAULO, \\
Ano de obtenção: 1973. \\
Orientador: YARO RIBEIRO GANDRA. \\
Palavras-chave: anemia; gestantes; Recem-Nascidos. \\
Grande área: Ciências da Saúde / Área: Nutrição. \\
Mestrado em Nutrição. \\
Universidade de São Paulo, USP, Brasil. \\
Titulo: AVALIACAO NUTRICIONAL INDIRETA DA POPULACAO URBANA DE \\
CACHOEIRA PAULSTA ATRAVES DA RENDA FAMILAR,Ano de Obtenção: \\
1970. \\
Orientador: YARO RIBEIRO GANDRA. \\
Palavras-chave: Avaliacao de Consumo; consumo alimentar; ESTADO \\
NUTRICIONAL. \\
Grande área: Ciências da Saúde / Área: Nutrição / Subárea: Análise \\
Nutricional de População. \\
Graduação em Quimica. \\
Universidade de São Paulo, USP, Brasil. \\
Graduação em Química. \\
Universidade de São Paulo, USP, Brasil.
\end{tabular}




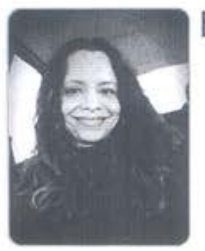

\section{Fabiana Corrêa Fernandes}

Endereço para acessar este CV: http://lattes.cnpq.br/7200651292538336

Ũitima atualização do currículo em 13/03/2014

Possui graduação em Nutrição pela Universidade Federal do Pará (1997). Especialização em Nutrição pela Faculdade de Medicina de Ribeirão Preto - USP (1998). Aluna de mestrado em Nutrição em Saúde Pública da Faculdade de Saúde Pública - USP. Atualmente é Especialista em Saúde da Autarquia Hospitalar Municipal de São Paulo atuando no Hospital Municipal Dr. Cármino Carcchio. Tem interesse em Políticas Públicas de Saúde e Nutrição, Avaliação Nutricional e Consumo Alimentar. (Texto informado pelo autor)

\section{Identificação}

Nome Fabiana Corrêa Fernandes

Nome em citaçöes bibliográficas FERNANDES, F. C.

\section{Endereço}

Endereço Profissional Autarquia Hospitalar Municipal de São Paulo, Prefeitura Municipal de Săo Paulo.

Avenida Celso Garcia - de 2483 ao fim - lado impar

Tatuapé

03063000 - São Paulo, SP - Brasil

Telefone: (11) 33947020

Formação acadêmica/titulação

$\begin{array}{ll} & \text { Mestrado em andamento em Nutrição em Saúde Pública. } \\ & \text { Universidade de São Paulo, USP, Brasil. } \\ & \text { Titulo: Evolução da alimentação de lactentes de } 6 \text { a } 24 \text { meses no } \\ & \text { Maranhão,Orientador: (Q) Sophia Cornbluth Szarfarc. } \\ & \text { Especialização em Especialização em Nutriçâo. (Carga Horária: 1900h). } \\ & \text { Hospital das Clínicas da Faculdade de Medicina de Ribeirão Preto. } \\ & \text { Titulo: Relatório de Atividades. } \\ & \text { Orientador: José Eduardo Dutra de Oliveira. } \\ & \text { Bolsista do(a): FUNDAP. } \\ & \text { Graduação em Nutrição. } \\ & \text { Universidade Federal do Pará, UFPA, Brasil. } \\ & \text { Titulo: Avaliação do Desempenho do Programa Nacional de Educação e } \\ & \text { Controle do Diabetes Mellitus Implantado nos Niveis Primário,Secundário e } \\ & \text { Terciário de Atenção à Saúde do Municipio de Belém. } \\ & \text { Orientador: Ana Lucia Rocha Faillace. }\end{array}$

Formação Complementar

2010 - 2010 Legislação e Aspectos Práticos em Vig. Sanitária. (Carga horária: 10h). Pró alimento Cursos e Capacitaçōes em Higiene Alimentar. 